\title{
Effect of Adipose-Derived Stem Cells on Induced Photoaging in the Skin of Adult Guinea Pig: Histological and Immunohistochemical Study
}

\section{Original Article}

\author{
Somaya A. Mohammed, Nevert F. Abd El Salam, Nagwa K. Kalleny, Nevine Bahaa \\ and Jolly M.W. Labib \\ Histology and Cell Biology Department, Faculty of Medicine, Ain Shams University, Cairo, \\ Egypt
}

\begin{abstract}
Introduction: The term photoaging describes the sun damaging effects on skin mainly due to chronic ultraviolet (UV) light exposure. The unsatisfactory results of the available anti-aging strategies raise the demand for alternative forms of treatments. Adipose-derived stem cells (ASCs) are available in abundant quantities, harvested by a minimally invasive procedure, safely transplanted and differentiated along multiple cell lineages. Subsequently, used in treatment of many diseases.

Aim: To assess the potential ability of ASCs to ameliorate skin changes induced by chronic exposure to artificial light source similar to the sun rays in its UVA and UVB spectrum in adult female guinea pigs.

Material and Methods: Adipose-derived stem cells were isolated from subcutaneous white adipose tissue of five adult human donors undergoing elective liposuction surgery. Twenty adult female guinea pigs were used and were randomly divided into two groups each was subdivided into two subgroups "five animals, each". Subgroup IA served as the control group. Subgroup IB was intradermally injected with phosphate buffered saline solution. Subgroup IIA served as the photoaging model. Subgroup IIB served as the photoaging model intradermaly injected with ASCs. Isolated stem cells were cultured and characterized. Skin specimens were prepared and examined using different histological and immunohistochemical techniques. Morphometric and statistical studies were also performed.

Results: Subgroup IIA showed various UV damaging effects in the skin epidermis and dermis, while ASCs injection in subgroup IIB resulted in partial restoration of the skin structure.

Conclusion: Intradermal injection of ASCs partially ameliorated the photo-damaging effects. Further studies are needed before ASCs clinical application.
\end{abstract}

Key Words: Adipose-derived stem cells, guinea pigs, photoaging, skin, ultraviolet light Revised: 25 March 2017, Accepted: 06 July 2017

Corresponding Author: Nevine Bahaa, Histology and Cell Biology Department, Faculty of Medicine, Ain Shams University, Tel.: 01124999934, E-mail: nevine_bahaaeldine@med.asu.edu.eg

ISSN: 1110-0559, 2017, Vol. 40, No. 2

\section{INTRODUCTION}

Skin is the window of human health, and its appearance mirrors body performance and functionality. With age, human skin undergoes changes. Skin aging due to physiological senescence is termed "intrinsic aging", while premature skin aging induced by exogenous factors as chronic light exposure, pollution, chemicals and toxins is termed "extrinsic aging"[1]. Among the extrinsic factors, ultraviolet (UV) radiation is considered as the most harmful to the skin. The environment is mainly exposed to UV radiation in the range of $290-380 \mathrm{~nm}$. It is estimated that up to $80 \%$ of the signs of skin aging result from prolonged exposure to UV radiation. Premature skin aging associated with UV radiation is known as photoaging ${ }^{[2]}$.
The UVB radiation represents only $0.5 \%$ of sunlight on average and is restricted to midday especially in spring and summer. However, UVA radiation exists in sunlight all through the whole day and throughout the whole year and it could be transmitted through glass, allowing exposure to UVA while driving or while indoors near windows ${ }^{[3]}$. The harmful effects of chronic UV light exposure became more pronounced due to the ozone layer depletion in the earth atmosphere. Also, living in hot region adds to the individual annual UV load ${ }^{[4]}$. Premature skin aging from UV irradiation is a cumulative process based on the degree of exposure to sunlight ${ }^{[5]}$. Although many individuals tried to avoid excessive exposure to UV radiation, it remains difficult to avoid occupational exposure. Numerous outdoor employees are occupationally exposed to UV radiation ${ }^{[2]}$. 
Photoaging is characterized by many clinical signs as well as changes in the histological pattern of the skin epidermis and dermis. Individuals of all skin types can manifest photoaging, and unfortunately, photocarcinogenesis could be the most serious complication of chronic UV radiation exposure $^{[6]}$.

Several anti-aging strategies were developed during the last few years. Currently available antiaging skin treatments used to prevent and/or repair symptoms of photoaging usually give unsatisfactory and sometimes unpredictable results for the patients ${ }^{[7]}$ as sunscreens $^{[8]}$, antioxidants ${ }^{[9]}$, retinoids ${ }^{[10]}$ and peels ${ }^{[11]}$. Other treatments associate with several adverse effects e.g. laser treatment may lead to thermal injury and post-inflammatory hyperpigmentation ${ }^{[12]}$. Also, despite the popularity of using over-the-counter topical formulations for mending photoaged skin, the evidence for their clinical efficacy and mechanism of action is often limited ${ }^{[13]}$. To date, the market is full of expensive skin care products that fail to provide the target effect, which is disappointing ${ }^{[14]}$.

The presence of the mesenchymal stem cells in adipose tissue has brought up a global effort to utilize these cells in therapy of a wide range of skin diseases $^{[15]}$. On clinical grounds, the use of ASCs can be much more convenient than the use of bone marrowderived mesenchymal stem cells (BMSCs). In fact, ASCs could be found in abundant quantities as the incidence of overweight and obese individuals are growing at alarming rates throughout the world. Also, adipose tissue could be harvested by a minimally invasive procedure, safely and effectively transplanted to autologous or allogeneic host and differentiated along multiple cell lineage pathways in a reproducible manner ${ }^{[16,17]}$.

In order to develop compounds that may protect against sun damage, hairless mice and guinea pigs have mainly been used. The skin of guinea pigs is a well-established animal model for studying skin diseases due to its resemblance with human $\operatorname{skin}^{[18]}$. Hence, guinea pigs were chosen for inducing a photoaging model in the present study.

\section{AIM OF THE WORK}

The current study aimed to isolate culture stem cells from human adipose tissue and to assess their ability to ameliorate skin changes in adult female guinea pigs induced by chronic exposure to artificial light source similar to the sun rays in its UVA and UVB spectrum.

\section{MATERIAL AND METHODS}

Twenty adult female guinea pigs of average weight 300 grams were purchased and housed in the Medical Research Center, Faculty of Medicine, Ain Shams University. They were housed in wire mesh cages under standard experimental conditions and were fed on standard diet with free access to water. After one week of acclimatization to the new environment, the animals were subjected to gentle shaving of the hair over the center of their backs with an electric clipper (HC7235, United, Greece) at a surface area measuring $2 \mathrm{~cm} \times 2 \mathrm{~cm}$ after sterilization of the area with betadine ${ }^{[19]}$. Then, random picking of animals from their cages was done to classify them into two groups, ten animals each.

Group I (Control group): which was further subdivided into two subgroups: Subgroup IA: Consisted of five guinea pigs, left undisturbed in their cages. Subgroup IB: Consisted of five guinea pigs, each was injected once with $0.8 \mathrm{ml}$ phosphate buffered saline solution (PBS) intradermaly within multiple sites in the shaved thin skin area.

Group II (Photoaged group): which was further subdivided into two subgroups: Subgroup IIA (photoaged untreated subgroup): Five guinea pigs, each was exposed to UVA + UVB irradiation for two weeks at the shaved areas. The animals of this subgroup were sacrificed one week later. Subgroup IIB (photoaged ASCs-treated subgroup): Five guinea pigs, each was exposed to UVA + UVB irradiation for two weeks. The animals were then injected with ASCs ( 1 X 105 cells in $0.8 \mathrm{ml}$ PBS for each animal). This was done once at multiple sites intradermaly in the thin skin of the shaved areas. This subgroup was sacrificed one week after ASCs injection ${ }^{[20]}$.

Guinea pigs of all four subgroups were sacrificed under anesthesia using $30 \mathrm{mg} / \mathrm{kg}$ pentobarbital ${ }^{[6]}$. Scarification was done after three weeks from the beginning of the experiment (the shaving day).

\section{Ultraviolet lamp and irradiation protocol}

The exposure to UV irradiation was performed with a solar simulator (Exo Terra Reptile UVB150, Rolf C. Hagen Co., MA, USA) with UV spectrum covering the UVA region $(320-400 \mathrm{~nm})$ and UVB region (280- $320 \mathrm{~nm}$ ). The shaved backs of guinea pigs of both subgroups of group II were exposed singly in a special cage to both UVA and UVB irradiation simultaneously. Exposure to UV irradiation continued five days a week for two weeks. Each session of exposure to irradiation lasted approximately 15 minutes with an irradiation dose of 150 $\mathrm{mJ} / \mathrm{cm} 2$. Under these conditions, guinea pigs did not show any erythema, edema, or scaling ${ }^{[21]}$

\section{Adipose-derived stem cells (ASCs) isolation and culture protocol}

Subcutaneous white adipose tissue samples were collected from five adult human donors (four females and one male) undergoing elective liposuction surgery according to Pallua and Kim (2014) ${ }^{[22]}$. Written consents were obtained before taking the samples. The donors age 
averaged between 18- 41 years. All patients were healthy and didn't suffer from either diabetes or hypertension. Fat was harvested under general anesthesia from the abdomen, or arms, or thighs with special sterile cannulas.

Subcutaneous lipoaspirated tissue fragments from each patient were washed extensively with PBS to remove any debris. Then $10 \mathrm{ml}$ of washed adipose tissue was digested with one mg collagenase (Serva Electrophoresis $\mathrm{GmbH}$, Mannheim, Germany) in Dulbecco Modified Eagle Medium (DMEM, Gibco/ BRL, Grand Island, New York, USA) for 30 minutes at $37^{\circ} \mathrm{C}$, under gentle agitation. The collagenase enzyme was inactivated with an equal volume of culture medium. Digested tissue was filtered and centrifuged at 1,280 rpm for 15 minutes. Erythrocytes were removed by treatment with a red blood cell lysis buffer (4-(2-hydroxyethyl)-1-piperazineethanesulfonic acid; HEPES). After centrifugation, the supernatant-containing the floating population of mature adipocytes-was discarded and the pellet containing the stromal vascular fraction (SVF) was retrieved. The cells were transferred to $50 \mathrm{~cm} 2$ tissue culture flasks containing DMEM supplemented with $10 \%$ fetal bovine serum (FBS) kept in $5 \% \mathrm{CO} 2$ at $37^{\circ} \mathrm{C}$ in a standard incubator (LAB-LINE CO2 Incubator, NuAire, USA). After an attachment period of 24 hours, nonadherent cells were removed by a PBS wash. Attached cells were cultured in DMEM supplemented with $10 \%$ FBS, $1 \%$ penicillin-streptomycin and $1.25 \mathrm{mg} / \mathrm{L}$ amphotericin B. The culture flasks were examined daily by an inverted microscope with fluorescence unit (Leica, Germany) and the medium was changed every 23- days. At a confluence of $80 \sim 90 \%$, cultures were washed twice with PBS, the cells were trypsinized with $0.25 \%$ trypsin in $1 \mathrm{mM}$ EDTA (Lonza, Belgium) for 10 minutes at $37^{\circ} \mathrm{C}$ and incubated for 30 minutes to remove the cells from the culture flask into suspension. The enzyme was later inactivated by adding an equal volume of culture medium and the suspension was centrifuged. After centrifugation, cells were resuspended with serum-supplemented medium and incubated in 50 $\mathrm{cm} 2$ tissue culture flask. The resulting cultures were referred to as first-passage cultures which were used for further characterization and differentiation of $\mathrm{ASCs}^{[23]}$.

The ASCs were labelled with a fluorescent dye (PKH26 Red Fluorescent Cell Linker Kit for General Cell Membrane Labelling, purchased from Sigma-Aldrich ${ }^{[24]}$. Isolated labelled human ASCs were then intradermaly injected to the shaved areas of the back of guinea pigs ( 1 X 105 cells in $0.8 \mathrm{ml}$ PBS for each animal) of group $\mathrm{II}^{[20]}$

\section{Characterization and Differentiation of Adipose- derived Stem Cells}

Adipose-derived stem cells in primary culture were characterized by their adhesiveness and fusiform shape. In addition, immunophenotyping using the flow cytometry was done for their surface markers CD31, CD34, CD45, CD90 and CD105 [25].

To verify their differentiation potential, ASCs were incubated in a medium known to induce osteogenic lineage. Osteogenic differentiation of isolated ASCs was induced by cells of the first passage cultivated for four weeks in specific media that was changed every three days. The culture medium was supplemented with 108$\mathrm{M}$ dexamethasone, $5 \mathrm{mg}$ ascorbic acid 2-phosphate ml-1 and $10 \mathrm{mM}$ b-glycerophosphate. Calcium deposition in differentiated cultures was revealed by staining with Alizarin red $\mathrm{S}$ stain ${ }^{[23]}$. Cultures were examined daily using Inverted Microscope with Fluorescence unit (Leica, Germany). The ASCs isolation, characterization and differentiation were conducted at the Medical Biochemistry Study Department, Faculty of Medicine, Cairo University.

\section{Processing of Thin Skin Specimens}

For light microscopic study, some shaved thin skin specimens from the backs of all animals were fixed in $10 \%$ formalin for one week then processed to obtain paraffin blocks. Five $\mu \mathrm{m}$ thick serial sections were cut and stained with Haematoxylin and Eosin stain (H\&E), Masson's trichrome stain for collagen fibers ${ }^{[26]}$ and Orcein stain for elastic fibers ${ }^{[27]}$. Immunohistochemical staining using the anti-melanosome HMB-45 antibody (code M0634, Dako) was performed with the Streptavidinbiotin immunoperoxidase technique, to detect immature melanosomes in melanocytes ${ }^{[28]}$. In addition, immunofluorescence examination of ASCs labelled with PKH26 was done ${ }^{[24]}$ to demonstrate and ensure the survival of injected ASCs in guinea pig skin specimens.

For Transmission Electron Microscopy (TEM), other small shaved thin skin specimens were fixed in buffered formol glutaraldehyde ${ }^{[26]}$. Ultra-thin sections were prepared, examined and photographed by Phillips EM208S transmission electron microscope (TEM) at Theodor Bilharz Research Institute and with JOEL (JEM1200EXII) transmission electron microscope at Faculty of Science, Ain Shams University, Cairo, Egypt.

\section{Morphometric studies and statistical analyses}

Epidermal and dermal measurements were done from five different fields from five serial stained sections of all animals of each group. This was done using the image analyzer Leica Q win V.3 program at the Histology Department, Faculty of Medicine, Ain Shams University. The computer was connected to a Leica DM2500 microscope (Wetzlar, Germany). Morphometric measurements included:

1- Total thickness of the epidermis in H\&E-stained sections.

2- Total thickness of the dermis in H\&E-stained sections. 
3- Optical density of the anti-melanosome HMB-45 antibody in immunohistochemically stained sections.

4- Area percentage of dermal collagen content in Masson's trichrome-stained sections.

5- Area percentage of dermal elastic fibers in orceinstained sections.

The results of the quantitative and morphometric analyses were calculated as the means \pm Standard Error of the Mean (SEM). Statistical analyses were performed using IBM SPSS Statistics version 20. Results were compared using the one-way analysis of variance (ANOVA), with post-hoc least significant difference (LSD) test as appropriate. Regarding the probability, the least significant level used was at $\mathrm{P}$ value less than 0.05 .

\section{RESULTS}

Adipose-derived stem cells culture and
characterization

The cultured ASCs expanded easily in vitro. At day ten of the primary culture the adherent cultured cells acquired a spindle fibroblast-like shape with long processes. They appeared with vesicular nuclei and granular cytoplasm. Some nuclei appeared with two nucleoli (Fig. 1).

Flow cytometry analysis done at the first-passage cultures confirmed isolation and characterization of the ASCs. Absence of cell surface markers CD31 and CD45 (endothelial and white blood cell markers, respectively) was confirmed indicating pure ASCs isolate without other unwanted cellular fractions. Adipose-derived stem cells co-expressed the positive cell surface markers CD34, CD90 and CD105 (Fig. 2).

The examination of ASCs after culture in osteogenic supplemented media for four weeks showed aggregates of calcium deposition which were stained strongly red with Alizarin red S stain (Fig. 3).

\section{Hematoxylin and Eosin and PKH26 results}

Examination of thin skin sections of both subgroups of the control group (IA and IB) showed comparable histological appearance and morphometric values.

Thin skin sections of the control group showed the epidermis and dermis separated by an irregular basement membrane (Figs. 4, 5). The epidermis was seen composed of a stratified squamous keratinized epithelium arranged in four layers. Stratum basale cells were resting on the basement membrane, and were represented by a single layer of cuboidal to low columnar cells with large oval basal vesicular nuclei. Some cells showed mitotic figures. Stratum spinosum was formed of several layers of polyhedral keratinocytes with rounded vesicular nuclei. Stratum granuolosum keratinocytes appeared flattened with numerous intensely basophilic keratohyalin granules. Stratum corneum was formed of a cornified layer composed of flat, homogenous keratinized non-nucleated cells (Fig. 5). Underneath the epidermis, the papillary layer of the dermis appeared as a thin layer of loose connective tissue immediately beneath the epidermis that formed the substance of the dermal papillae interdigitating with epidermal rete ridges. Deep to the papillary dermis, and not sharply demarcated form it lied the reticular dermis, appearing thicker and less cellular than the papillary dermis. The dermis was rich in hair follicles and sebaceous glands (Fig. 4). Mean epidermal and dermal thickness was measured as $(46.12 \pm 1.33)$ and $(1042.78 \pm 12.69)$, respectively (Histogram 1).

Sections of the photoaged untreated subgroup (IIA) showed variable histological changes with patchy distribution. Demarcation of epidermal layers was hardly observed. Most of the keratinocytes appeared with dense shrunken nuclei and vacuolated cytoplasm. No mitotic figures could be detected in the sections. Stratum corneum appeared detached, disorganized and fragmented (Figs. 6, 7). The hair follicles were scanty, rarified, disorganized and the nuclei of their cells were pyknotic (Fig. 6). Both mean epidermal and dermal thickness were significantly decreased $(\mathrm{p}<0.05)$ as compared to the control subgroup IA, measuring $(15.89 \mu \mathrm{m} \pm 0.47)$ and (969.06 \pm 15.88$)$, respectively (Histogram 1$)$.

Sections of the ASCs-treated photoaged subgroup (IIB) examined with fluorescence microscope revealed positive fluorescence of PKH26 labelled ASCs in the dermis of the skin. This confirmed the presence of the injected cells in the guinea pig skin (Fig. 8). By H\&E, partial restoration of the structure of the epidermis and dermis was observed (Figs. 9, 10). Most of the keratinocytes in stratum basale and spinosum showed vesicular nuclei. Some keratinocytes of stratum spinosum were seen with vacuolated cytoplasm and deeply stained nuclei. Stratum corneum almost restored its regular appearance. There was an apparent increase in the number of hair follicles as compared to the photoaged subgroup (Fig. 10). Epidermis appeared of various thicknesses in different areas, but was overall significantly increased $(\mathrm{p}<0.05)$ as compared to the photoaged untreated subgroup (Figs. 9, 10), measuring $(37.28 \pm 0.80)$. However, this value was significantly decreased $(p<0.05)$ when compared to the control subgroup IA (Histogram 1). The mean dermal thickness was significantly increased $(p<0.05)$ as compared to both; the photoaged untreated subgroup IIA and the control subgroup IA (Fig. 9), measuring 1161.24 \pm 21.36 (Histogram 1). 


\section{Masson's trichrome-stained sections}

The control group sections showed collagen fibers as fine interlacing green bundles in the papillary dermis and thick, irregular green bundles in the reticular dermis (Fig. 11). Mean area percentage of dermal collagen measured (30.43 \pm 1.56$)$ (histogram 2).

Sections of the photoaged untreated subgroup (IIA) showed thin and fragmented collagen fibers leaving empty areas (Fig. 12). A significant decrease $(p<0.05)$ in mean collagen bundles area percentage was detected as compared to the control subgroup IA, measuring $(4.52 \pm 0.71)$ (Histogram 2).

The dermal collagen of the photoaged ASCstreated subgroup (IIB) was apparently comparable to the control group, showing interlacing fine collagen bundles in the papillary dermis and thick bundles in the reticular dermis (Fig. 13). A significant increase in dermal collagen content $(p<0.05)$ was detected as compared to the photoaged untreated subgroup IIA, and was non-significantly increased $(\mathrm{p}>0.05)$ as compared to the control subgroup IA, measuring $(31.29 \pm 2.61)$ (Histogram 2).

\section{Orcein stained-sections}

Sections of the control group showed reddish brown sparse, thread-like elastic fibers forming an irregular network in the papillary dermis. However, the reticular dermis contained coarser elastic fibers (Fig. 14). Mean area percentage of dermal elastic fibers measured as $2.78 \pm 0.38$ (Histogram 2)

Short and fragmented elastic fibers were seen in Orcein-stained sections of the photoaged untreated subgroup (IIA). In addition, condensed and disorganized elastic fibers with deposition of thick, amorphous elastotic material were detected under the epidermis (Fig. 15). A significant increase $(p<0.05)$ in mean area percentage of elastic fibers was detected as compared to the control subgroup IA, measuring $11.28 \pm 0.70$ (Histogram 2).

Orcein-stained sections of the photoaged ASCstreated subgroup (IIB) showed elastic fibers comparable to those of the control group. Elastic fibers in the papillary dermis formed an irregular network, with thicker elastic fibers in the reticular dermis (Fig. 16). A significant decrease in dermal collagen content $(p<0.05)$ was detected as compared to the photoaged untreated subgroup IIA, measuring $(5.28 \pm 0.51)$. However, it was significantly increased $(\mathrm{p}<0.05)$ when compared to the control subgroup IA (Histogram 2).

\section{Immunohistochemically-stained sections}

Sections of the control group showed positive antimelanosome HMB-45 antibody immunoreactivity revealed by brownish granular cytoplasmic reaction seen in melanocytes among cells of the basal layer of the epidermis (Fig. 17). Mean optical density of HMB45 immunoreactivity measured $0.22600 \pm$ (Histogram 3 ).

Sections of the photoaged untreated subgroup (IIA) revealed a strong dark granular cytoplasmic reaction in melanocytes between keratinocytes of basal layer of epidermis (Fig. 18). Mean anti-melanosome HMB-45 antibody immunoreactivity was significantly increased $(\mathrm{p}<0.05)$ as compared to the control subgroup IA, measuring $0.946 \pm 00$ (Histogram 3).

Examination of sections of the photoaged ASCs-treated subgroup (IIB) revealed decreased immunoreactivity as compared to the photoaged subgroup IIA(Fig. 19). Statistically, significant decreased optical density $(\mathrm{p}<0.05)$ was detected as compared to the photoaged untreated subgroup IIA, measuring $(0.714 \pm 00)$. However, this was significantly increased $(p<0.05)$ when compared to the control subgroup IA (Histogram 3).

\section{Transmission electron microscopic results (TEM)}

Sections of the control group showed the keratinocytes in stratum basale formed of low columnar cells resting on basal lamina. The cells showed euchromatic nuclei and the cytoplasm contained various amounts of electron dense melanin granules. The cells were connected to each other by desmosomes and to the basal lamina by hemidesmosomes (Fig. 20). Stratum spinosum cells appeared polyhedral in shape with euchromatic rounded nuclei. The cells were attached to each other by desmosomes (Fig. 21). Keratinocytes in stratum granulosum contained electron dense non membranous keratohyalin granules and bundles of tonofilaments. The interface between keratinocytes of stratum granulosum and stratum corneum showed multiple lipid lamellae (Fig. 22). Fibroblasts in the underlying dermis appeared with euchromatic nuclei (Fig. 20).

Examination of sections of the photoaged untreated subgroup (IIA) showed the strata basale and spinosum with variable degrees of affection. Some keratinocytes appeared with an irregular outline with irregular and shrunken nuclei exhibiting peripherally condensed heterochromatin. Most of the kertainocytes showed many melanin granules in the cytoplasm. Desmosomes appeared distorted and hemidesmosomes appeared disrupted and detached from the basal lamina in some areas (Fig. 23). Keratohyalin granules appeared decreased in amount in keratinocytes of stratum granulosum. Lipid 
lamellae were thin and sparse as compared to that of the control group (Fig. 24). Dermal fibroblasts appeared with vacuolated cytoplasm and irregular electron dense fragmented nuclei. Dermal collagen fibers appeared fragmented showing empty areas (Fig. 25).

Examination of thin skin sections of the photoaged ASCs-treated subgroup (IIB) subgroup showed many keratinocytes in the strata basale and spinosum with euchromatic nuclei. Numerous intact desmosomes and hemidesmosomes were seen attaching keratinocytes together and to the basal lamina, respectively. The epidermis showed reduced melanin content as compared to the photoaged untreated subgroup IIA (Fig. 26). Keratinocytes of stratum granulosum showed large content of keratohyalin granules. The lipid lamellae at the stratum corneum-stratum granulosum interface were multiple and ample compared to the photoaged untreated subgroup IIA (Fig. 27). Dermal fibroblasts were observed with euchromatic nuclei and nearby collagen bundles comparable to those in subgroup IA (Fig. 25).

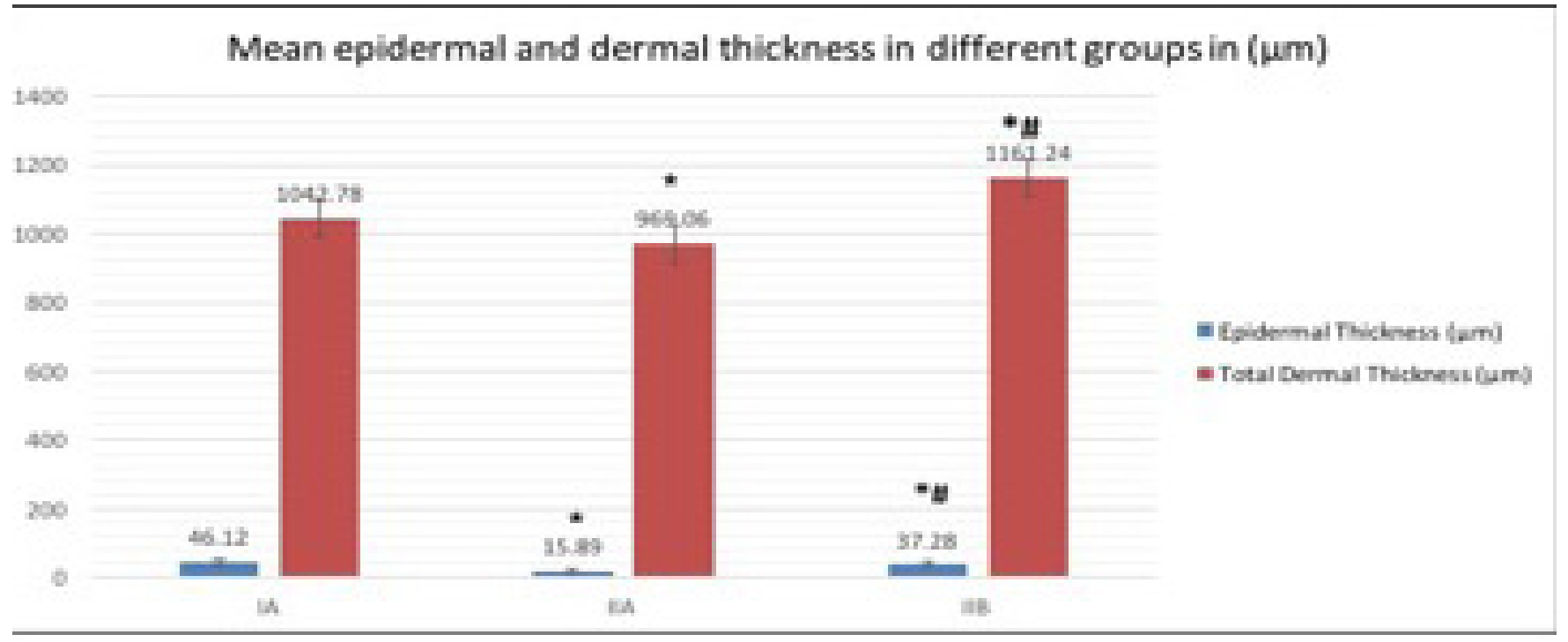

Valucs represent mein \pm SEM.

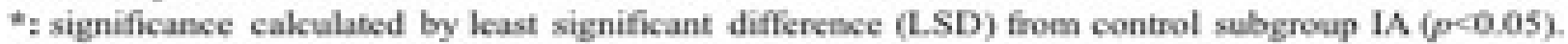

H: significanse cakulated by LSD from UV ind ated subgroup IIA (F-0,05)

Histogram 1: Showing differences in mean epidermal and dermal thicknesses between groups

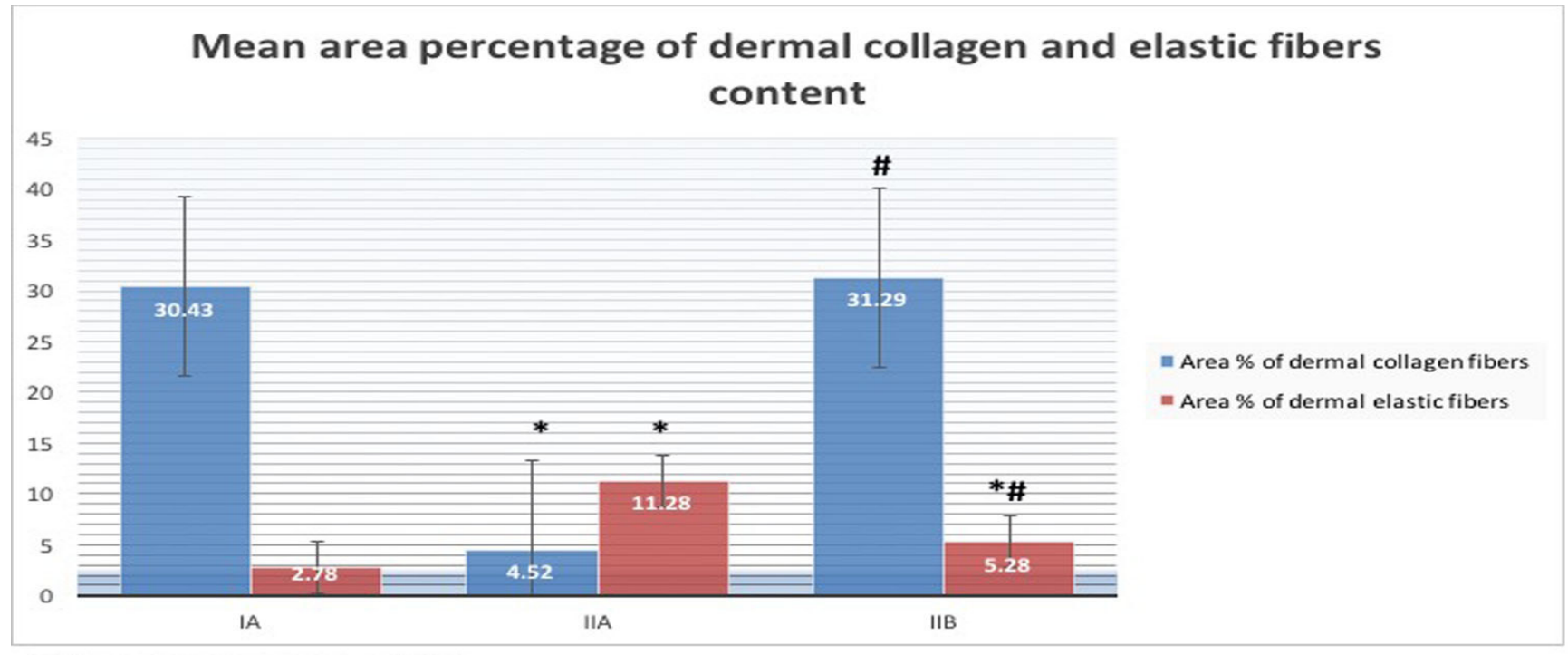

Values represent mean \pm SEM.

*: significance calculated by least significant difference (LSD) from control subgroup IA $(p<0.05)$.

\#: significance calculated by LSD from UV irradiated subgroup IIA $(p<0.05)$

Histogram (2): Showing differences in mean area percentage of dermal collagen and dermal elastic fibers between groups 


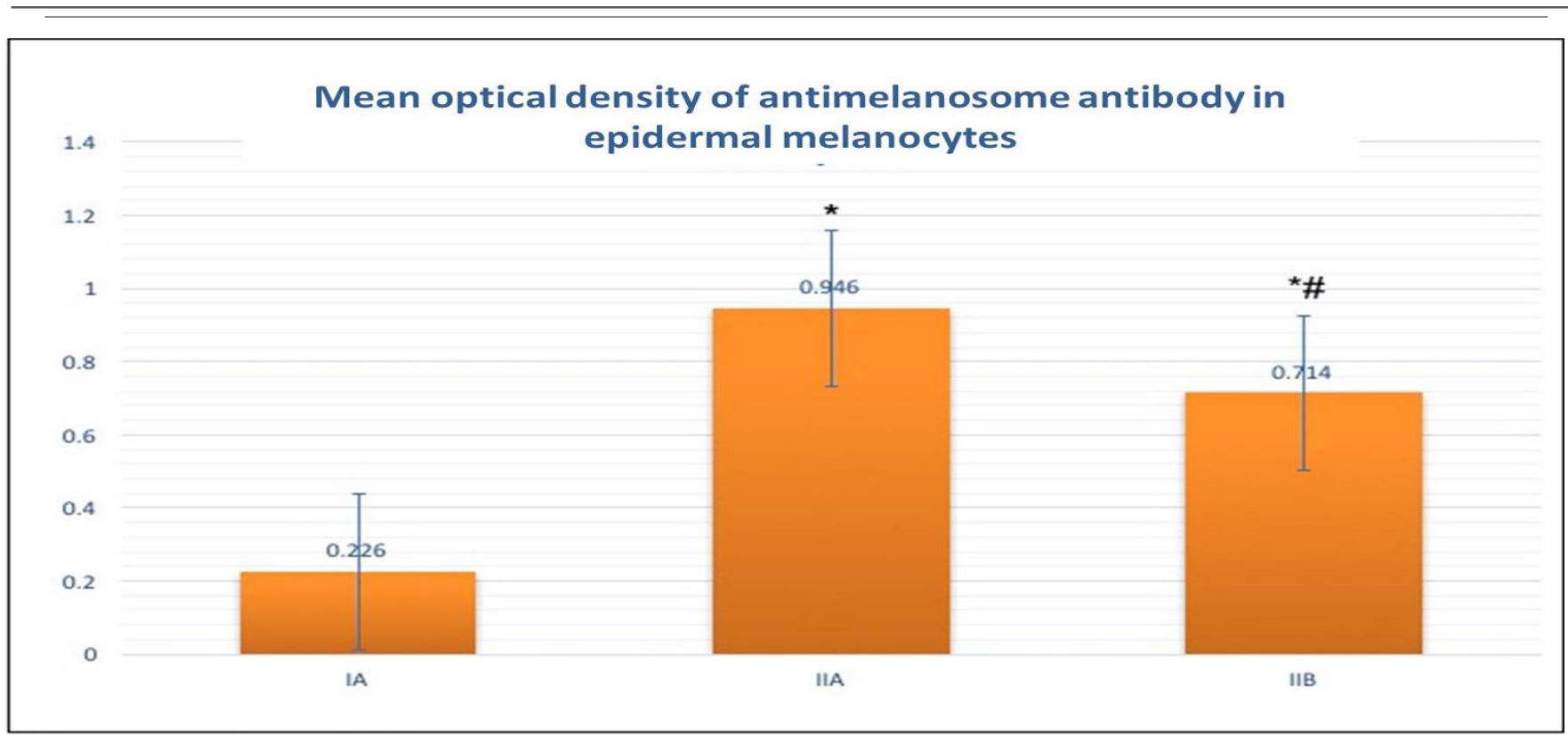

Values represent mean \pm SEM.

*: significance calculated by least significant difference (LSD) from control subgroup IA $(p<0.05)$.

\#: significance calculated by LSD from UV irradiated subgroup IIA $(p<0.05)$

Histogram (3): Showing differences in mean optical density of melanosomes between groups

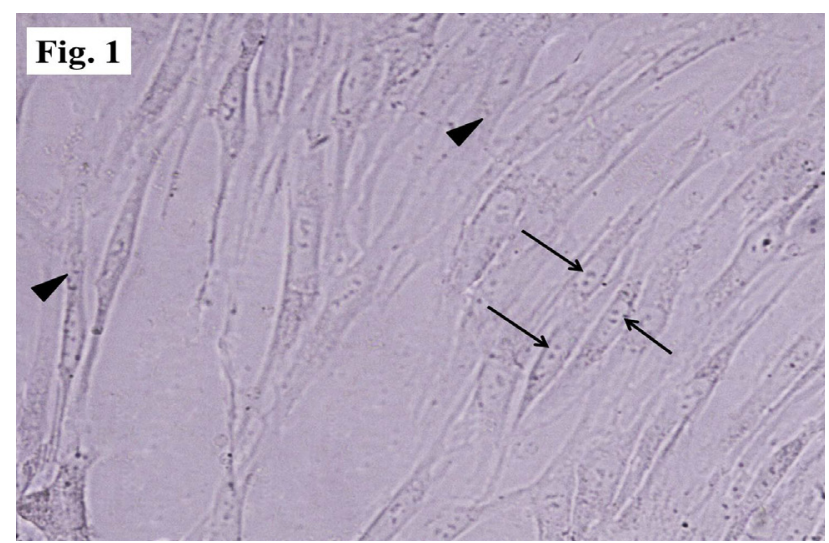

Fig. 1: Day ten of the primary culture showing the fibroblastlike ASCs. Notice cells with double nucleoli $(\uparrow)$ and granular cytoplasm ( $\mathbf{\Delta})$.

(Phase contrast microscope $\mathrm{x}$ 200)

Fig. 2
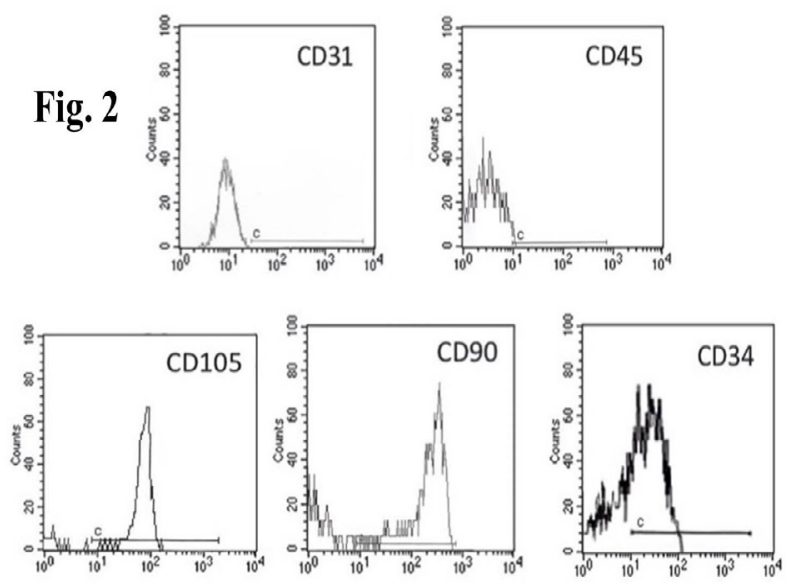

Fig. 2: Showing ASCs characterization. The ASCs are seen negative for the markers CD31 and CD45 and positive for the markers CD34, CD90 and CD105. (Flow cytometry analysis)

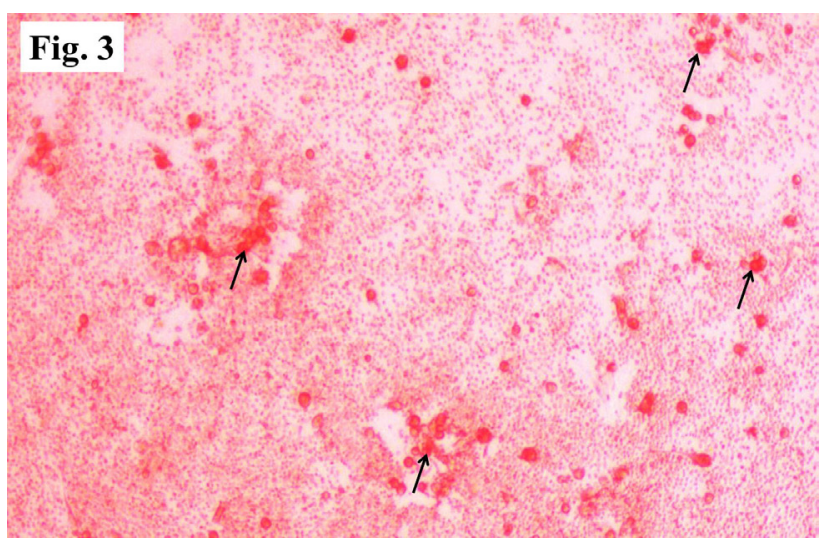

Fig. 3: Showing induction of osteogenic differentiation of ASCs appearing as red patches of calcium deposits $(\uparrow)$.

(Phase contrast microscope, Alizarin red S stain x 200)

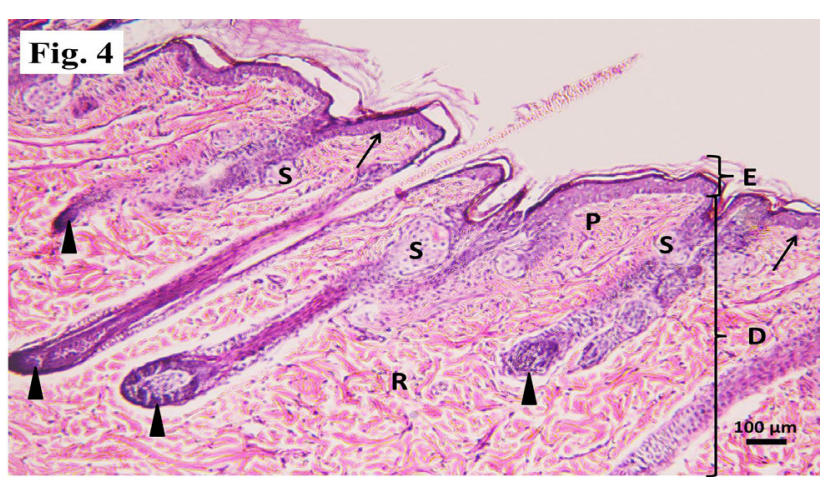

Fig. 4: Showing stratified squamous keratinized epithelium of the epidermis (E), and the connective tissue of dermis (D) with an irregular dermo-epidermal junction in between $(\uparrow)$. The dermis consists of a superficial papillary layer (P) and a deep reticular layer $(\mathrm{R})$. Notice hair follicles $(\boldsymbol{\Delta})$ and accompanying sebaceous glands $(\mathrm{S})$. 


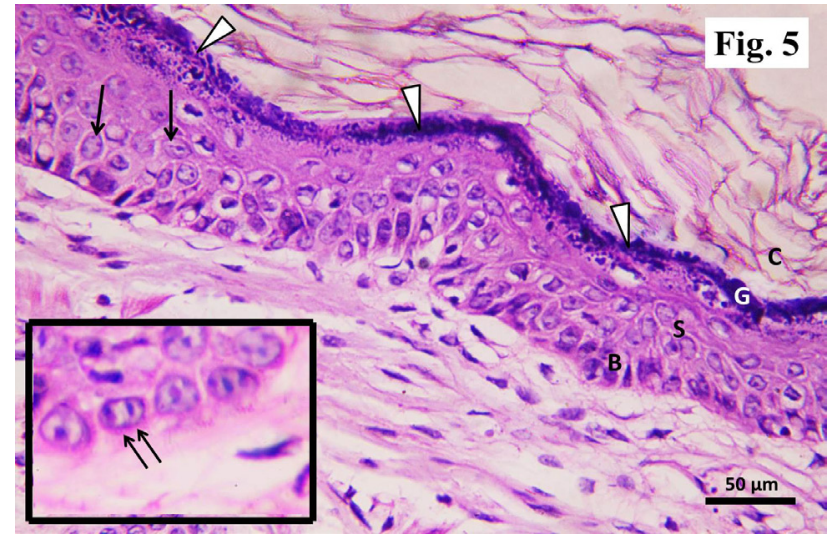

Fig. 5: Showing keratinocytes of the stratum basale (B), the stratum spinosum $(\mathrm{S})$, the stratum granulosum $(\mathrm{G})$, and the stratum corneum (C). The stratum spinosum cells have rounded central vesicular nuclei $(\uparrow)$. The intensely basophilic keratohyalin granules are seen in keratinocytes of stratum granulosum $(\Delta)$. Inset shows mitotic figures in keratinocytes of stratum basale $(\uparrow \uparrow)$

(Control subgroup IA, H\&E x400, Inset x1000)

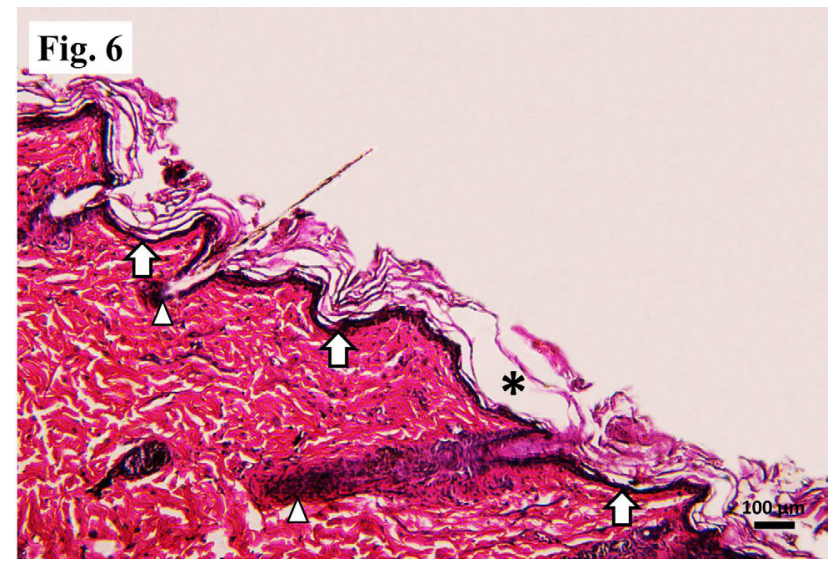

Fig. 6: Showing an apparently thin epidermis ( $\uparrow)$. The stratum corneum is seen detached and fragmented $(*)$. Notice the rarefied hair follicles $(\Delta) . \quad$ (Photoaged untreated subgroup, H\&E x 100)

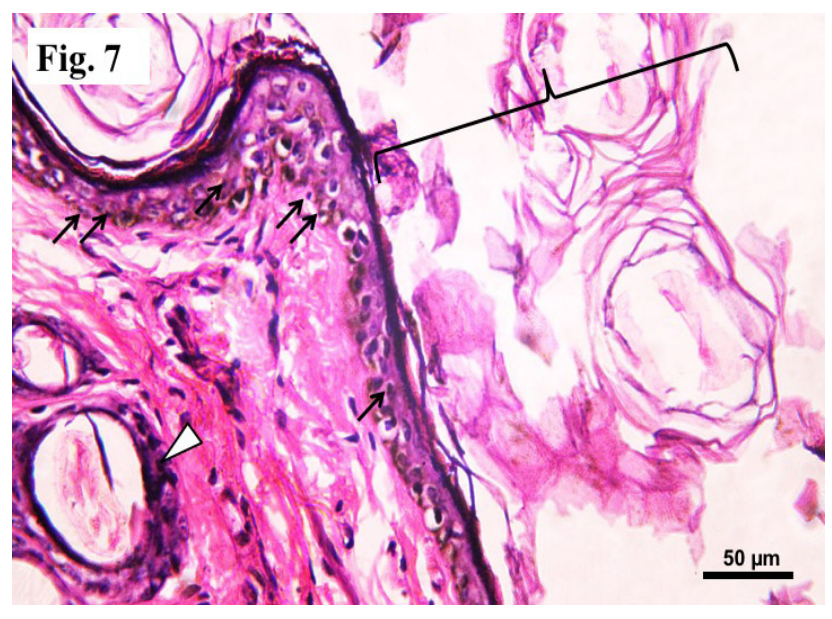

Fig. 7: Some keratinocytes of stratum basale and stratum spinosum show pyknotic nuclei and vacuolated cytoplasm $(\uparrow)$. Nuclei of hair follicles are also pyknotic $(\Delta)$. Notice the detached, fragmented and peeled out stratum corneum (\{).

(Photoaged untreated subgroup, H\&E x 400)

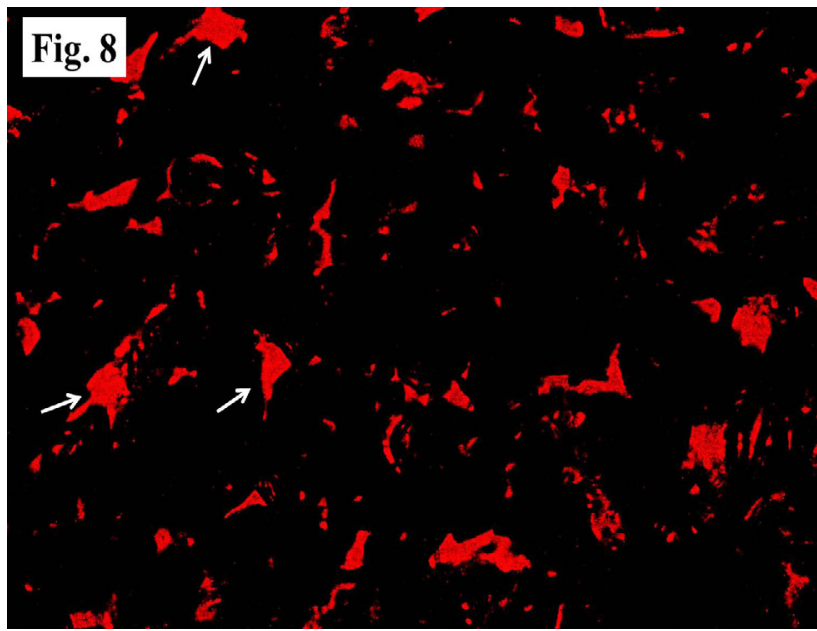

Fig. 8: A fluorescence micrograph of the dermis of the skin of guinea pig showing positive PKH26 labelled cells ( $\uparrow$ ).

(Photoaged ASCs-treated subgroup,

Fluorescent Microscope x 200)

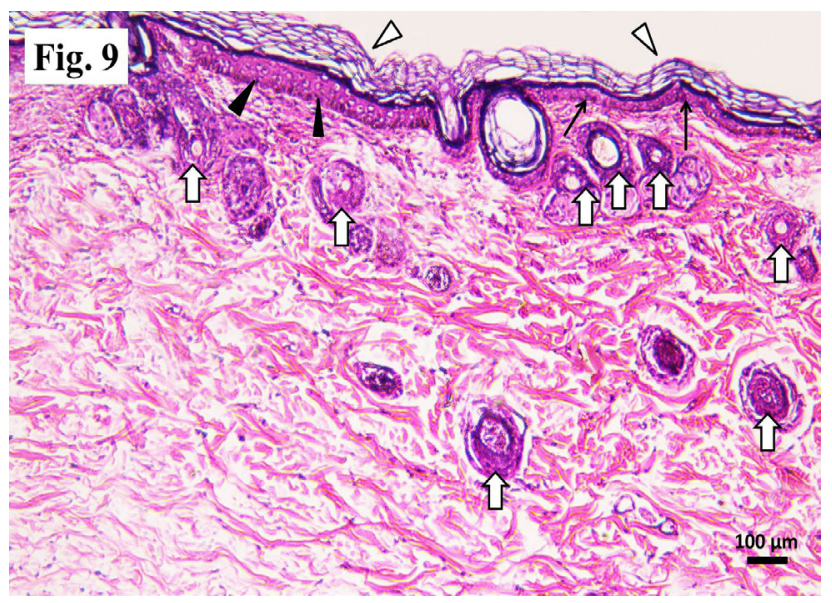

Fig. 9: Showing thick epidermis in some areas $(\boldsymbol{\Delta})$ and thin epidermis in other areas $(\uparrow)$. Regular arrangement of the stratum corneum can be seen $(\nabla)$. Notice the large number of hair follicles $(\bigcap)$. (Photoaged ASCs-treated subgroup, H\&E x 100)

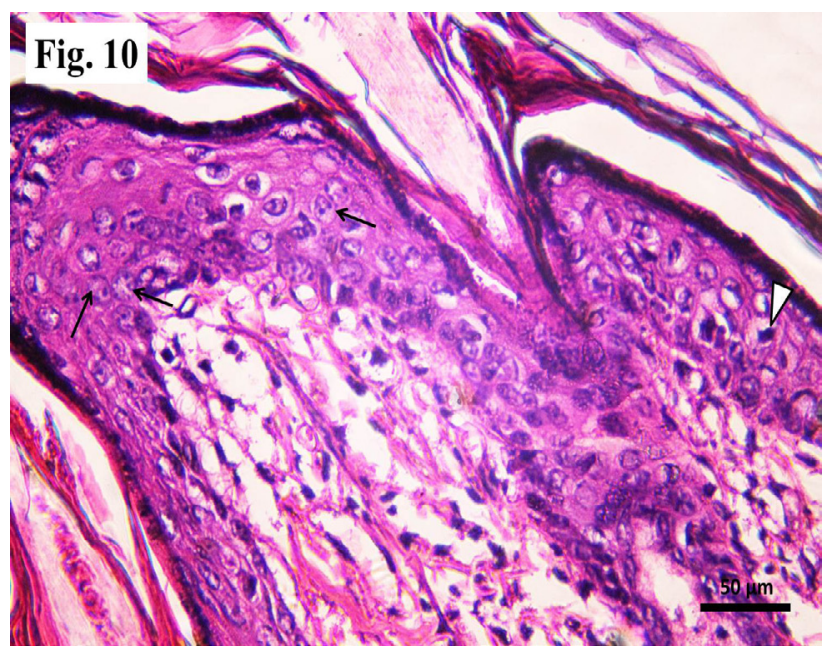

Fig. 10: Most of cells of strata basale and spinosum show vesicular nuclei $(\uparrow)$. Some keratinocytes of stratum spinosum are seen with vacuolated cytoplasm and pyknotic nuclei $(\nabla)$.

(Photoaged ASCs-treated subgroup, H\&E x 400) 


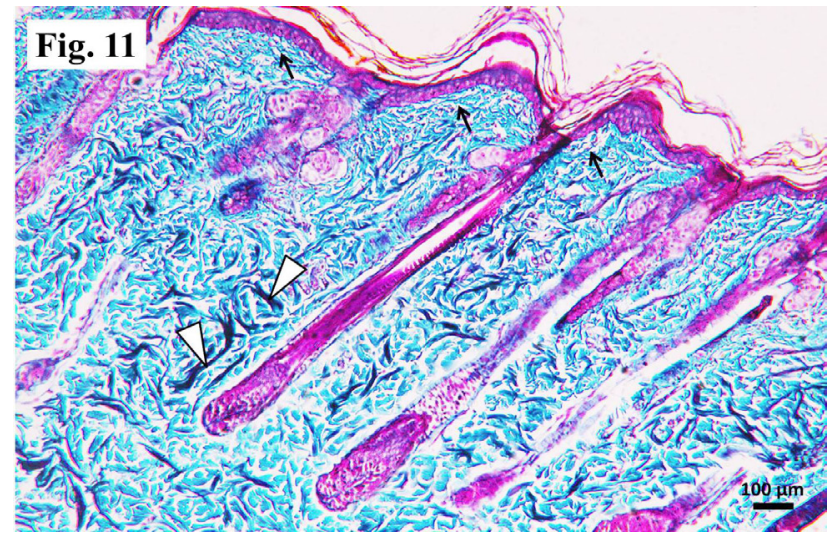

Fig. 11: Showing collagen content of the papillary dermis collagen as fine interlacing bundles $(\uparrow)$. In the reticular dermis collagen is seen deposited in coarse, wavy bundles running in different directions $((\nabla)$.

(Control group, Masson's Trichrome x 100)

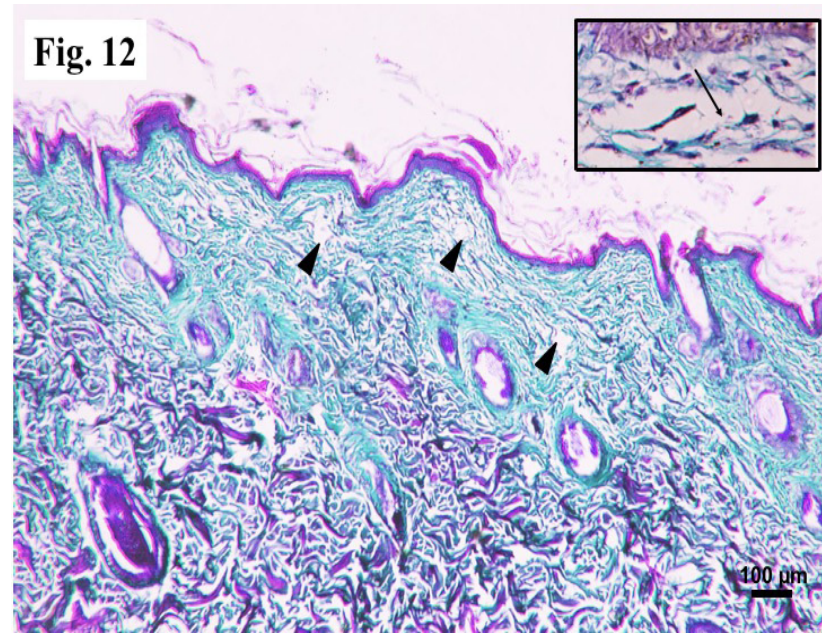

Fig. 12: Showing loosely packed and apparently thin collagen bundles in the papillary dermis with some areas devoid of collagen $(\mathbf{\Delta})$. Inset: showing the fragmentation of collagen bundles $(\downarrow)$. (Photoaged untreated subgroup, Masson's Trichrome x 100), Inset x 400)

Fig. 13

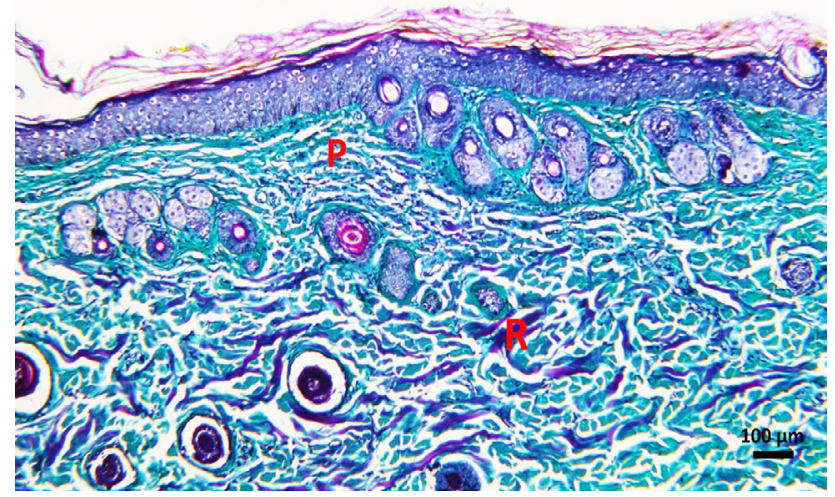

Fig. 13: Showing interlacing fine collagen bundles in the papillary dermis $(\mathrm{P})$. Thicker collagen bundles appear in the reticular dermis $(\mathrm{R})$.

(Photoaged ASCs-treated subgroup, Masson's Trichrome x 100)

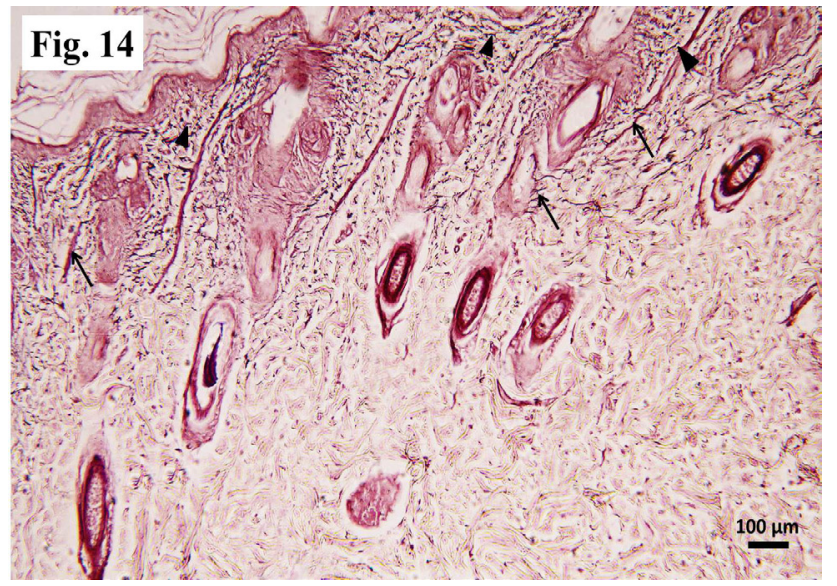

Fig. 14: The dermal elastic fibers appear as thin branched reddish brown fibers in the papillary dermis $(\boldsymbol{\Delta})$. However, they appear thicker in the reticular dermis $(\uparrow)$.

(Control group, Orcein x 100)

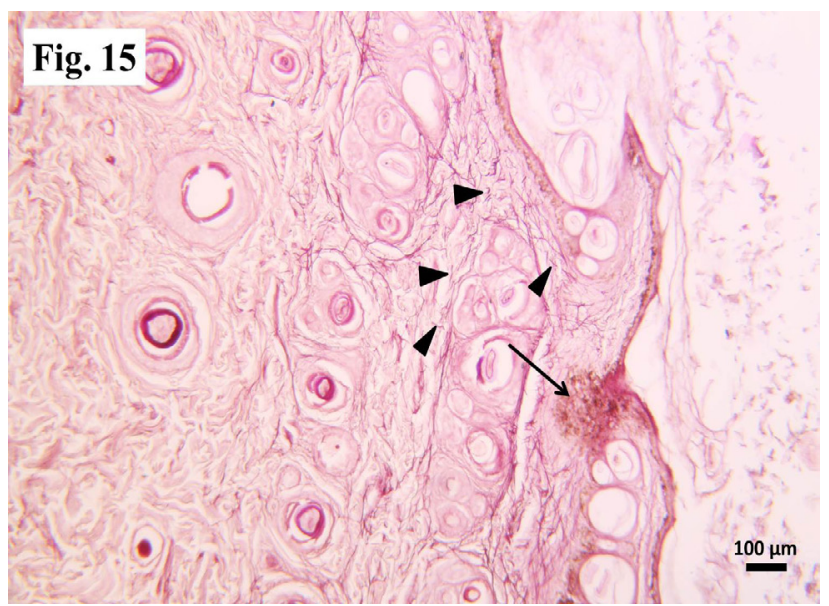

Fig. 15: Showing shortened and fragmented $(\boldsymbol{\Delta})$ elastic fibers. Notice increased deposition of thick, tangled, amorphous elastotic material $(\uparrow)$.

(Photoaged untreated subgroup, Orcein x 100)

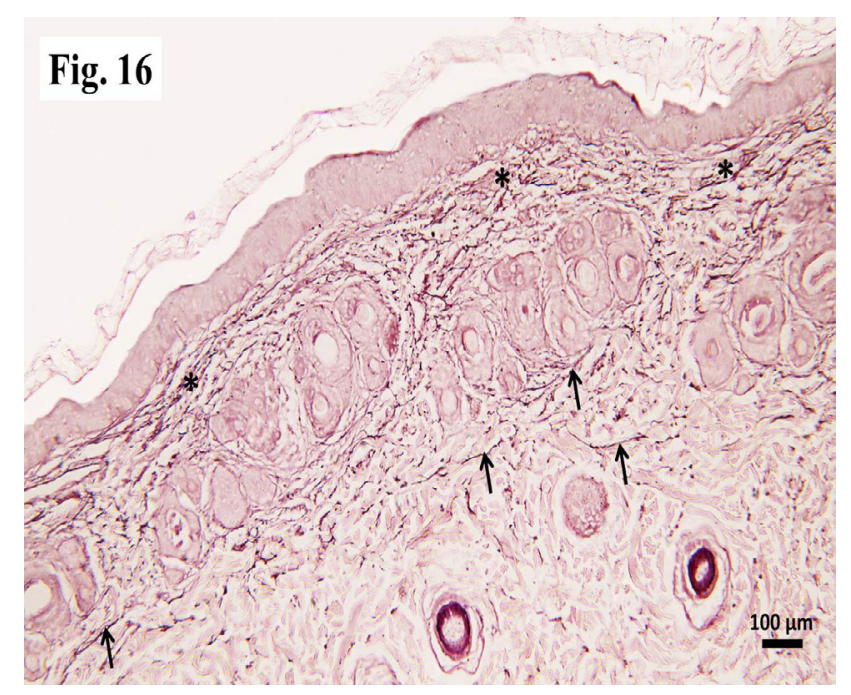

Fig. 16: Showing an irregular network of elastic fibers in the papillary dermis $(*)$, and thicker elastic fibers in the reticular dermis $(\uparrow)$.

(Photoaged ASCs-treated subgroup, Orcein x 100) 


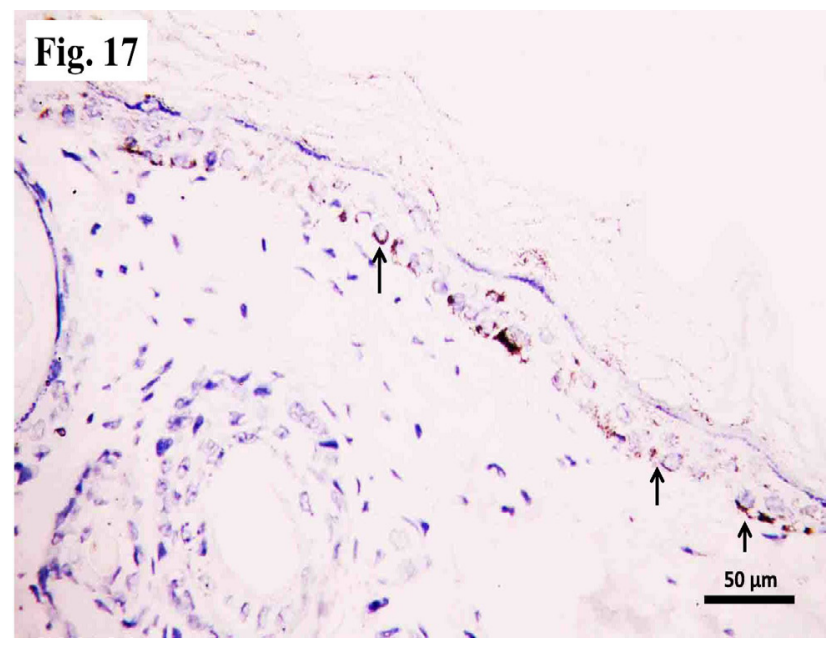

Fig. 17: Showing positive immunoreactivity of melanosomes inside active melanocytes appearing as brownish cytoplasmic granules ( $\uparrow$ ).

(Control group, Streptavidin-biotin technique $\mathrm{x} 400)$
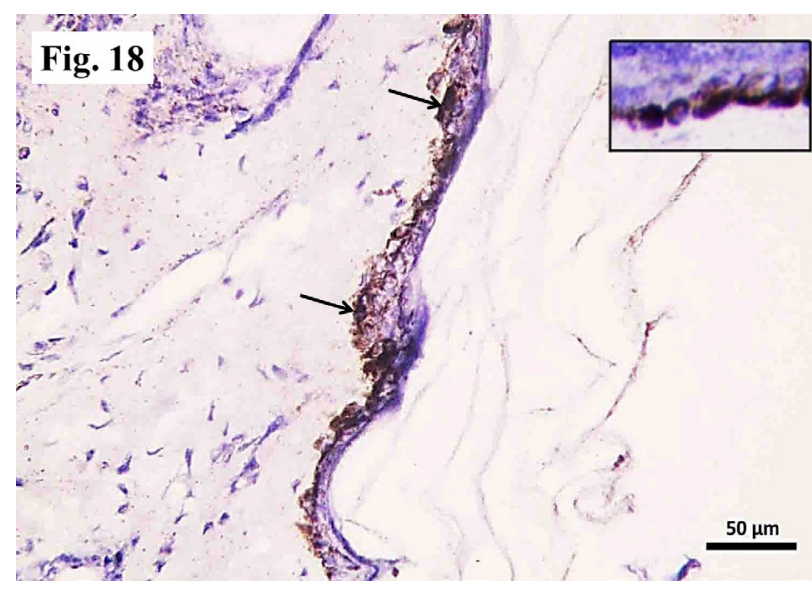

Fig. 18: Showing an apparent increase in the positive immunoreactivity of anti-melanosome antibody $(\uparrow)$. Notice the positive cytoplasmic granules in melanocytes in the inset.

(Photoaged untreated subgroup, Streptavidin-biotin technique $\mathrm{x} 400$, Inset x1000)

Fig. 19

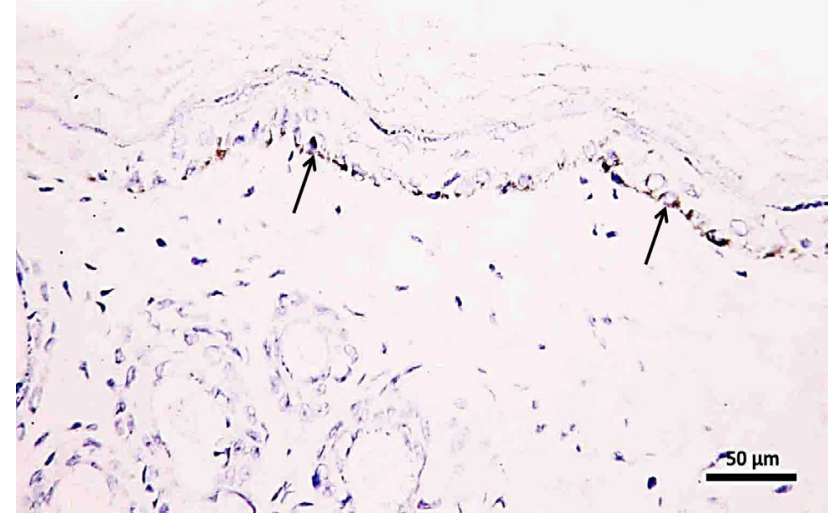

Fig. 19: Showing positive immunoreactivity of anti-melanosome antibody $(\uparrow)$ in melanocytes.

(Photoaged

ASCs-treated

subgroup, Streptavidin-biotin technique x 400)

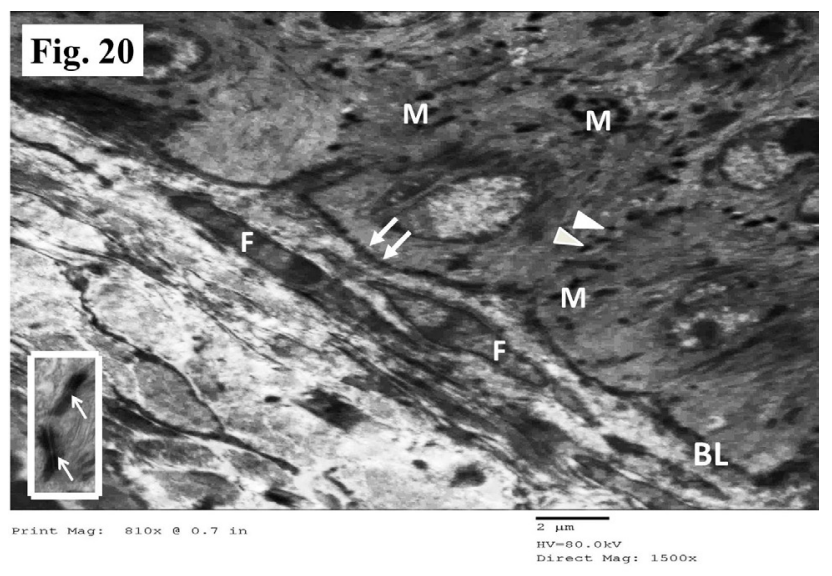

Fig. 20: Showing keratinocytes of the stratum basale resting on basal lamina (BL), attached to it by hemidesmosomes ( $\uparrow$ ) and to each other by desmosomes $(\nabla)$. Keratinocytes have euchromatic nuclei and melanin granules (M) are also seen. Notice the fibroblasts (F) in papillary dermis. Inset shows desmosomes between keratinocytes $(\uparrow)$.

(Control group, TEM x 1500, Inset x 6000)

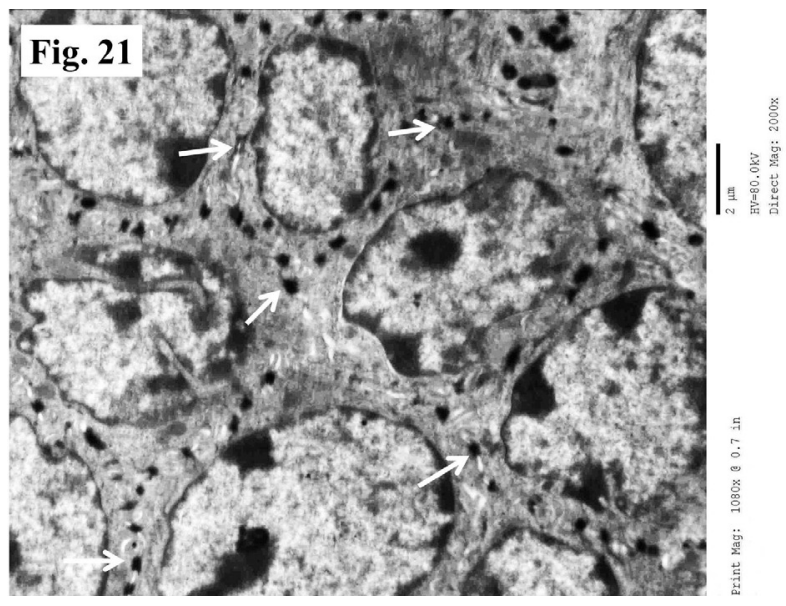

Fig. 21: Showing euchromatic nuclei in stratum spinosum cells The adjacent cell membranes are studded with desmosomes $(\downarrow)$.

(Control group, TEM x 2000)

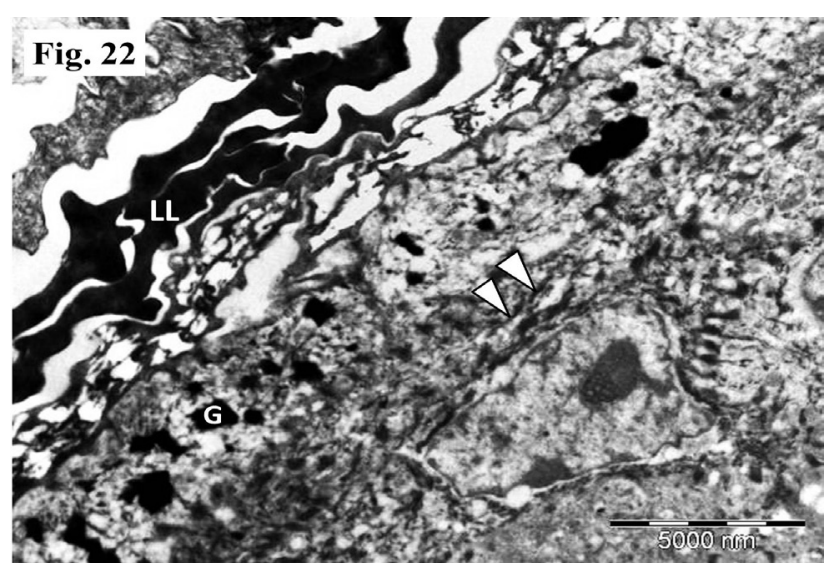

Fig. 22: Showing cells of stratum granulosum filled with bundles of tonofilaments $(\nabla)$ and keratohyalin granules $(\mathrm{G})$. The stratum corneum-stratum granulosum interface shows multiple lipid lamellae (LL).

(Control group, TEM x 4400) 


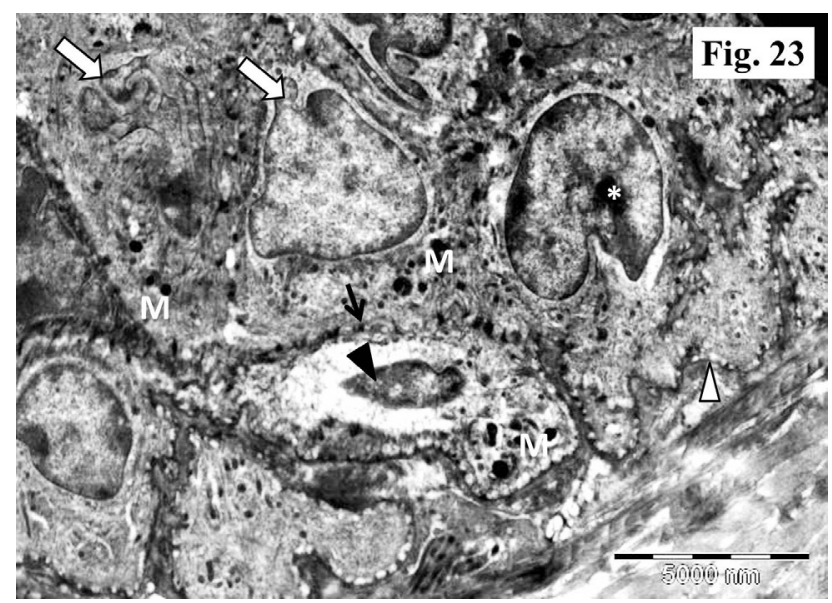

Fig. 23: Showing irregular keratinocytes of strata basale and spinosum. Some cells of stratum basale show irregular nuclei (*) while others show shrunken nuclei $(\boldsymbol{\Delta})$ with vacuolated cytoplasm. Stratum spinosum cells show abnormal irregularly shaped nuclei $(\downarrow)$. Most of cells show melanin granules in their cytoplasm (M). Notice desmosomes $(\downarrow)$ and disrupted hemidesmosomes in basal cells $(\Delta)$.

(Photoaged untreated subgroup, TEM x 4400)

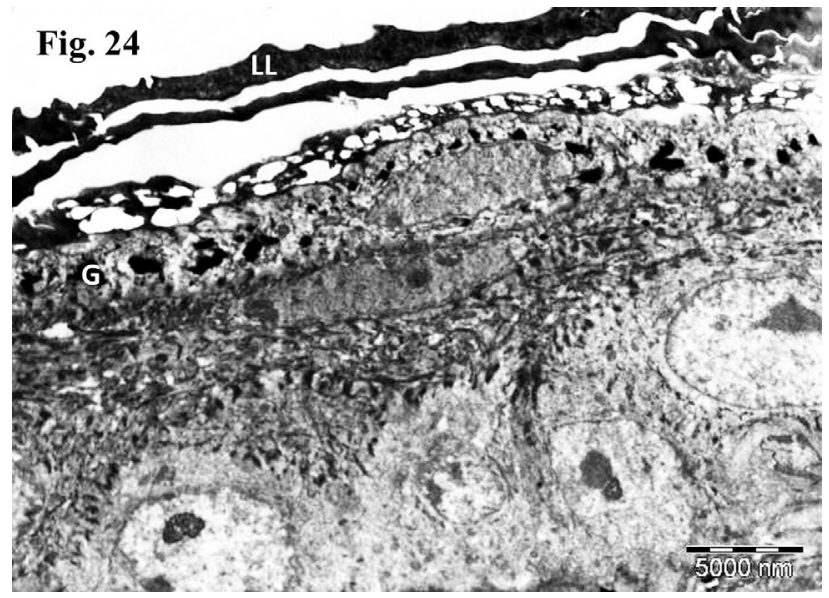

Fig. 24: Showing the keratohyalin granules $(G)$ keratinocytes of stratum granulosum. Lipid lamellae (LL) appear thin and sparse.

(Photoaged untreated subgroup, TEM x 4400)

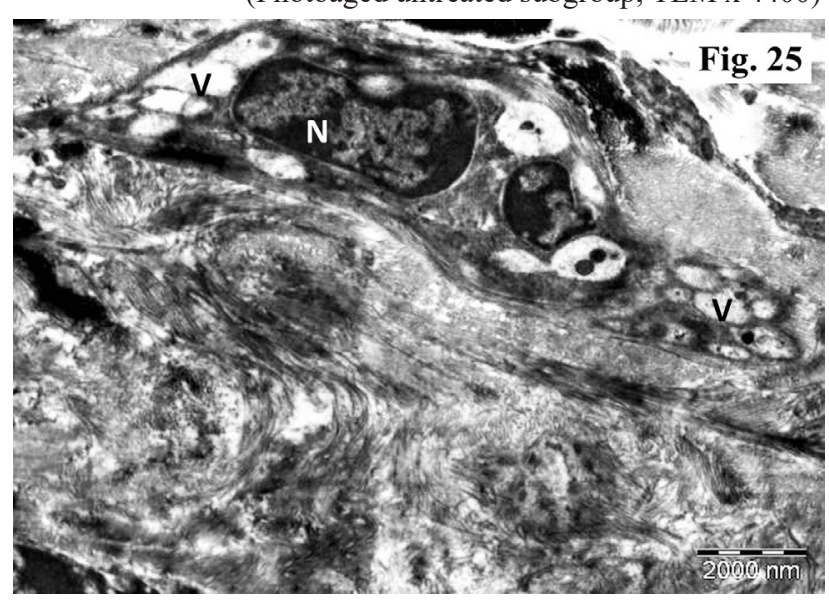

Fig. 25: Showing a fibroblast in the dermis with an electron dense nucleus (N) and many cytoplasmic vacuoles (V). Electron lucent areas devoid of collagen can be seen $(\uparrow)$.

(Photoaged untreated subgroup, TEM x 5600)

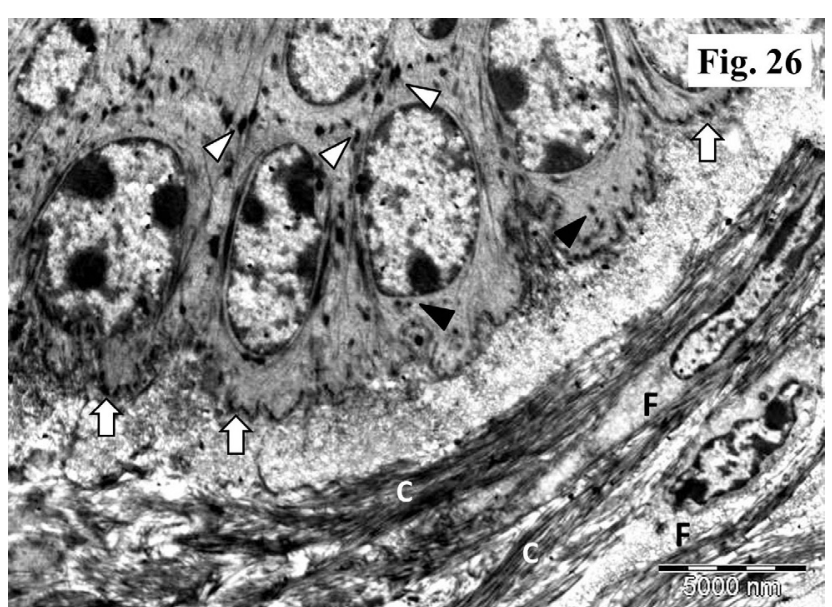

Fig. 26: Showing keratinocytes of stratum basal with euchromatic nuclei and hemidesmosomes ((П).). Desmosomes can be seen ( $(\nabla)$ with adjacent cells. The nuclei of stratum spinosum cells appear euchromatic. Notice few melanin granules $(\boldsymbol{\Delta})$. Active fibroblasts $(\mathrm{F})$ with euchromatic nuclei can be seen in papillary dermis with nearby bundles of collagen fibers (C).

(Photoaged ASCs-treated subgroup, TEM x 3500)

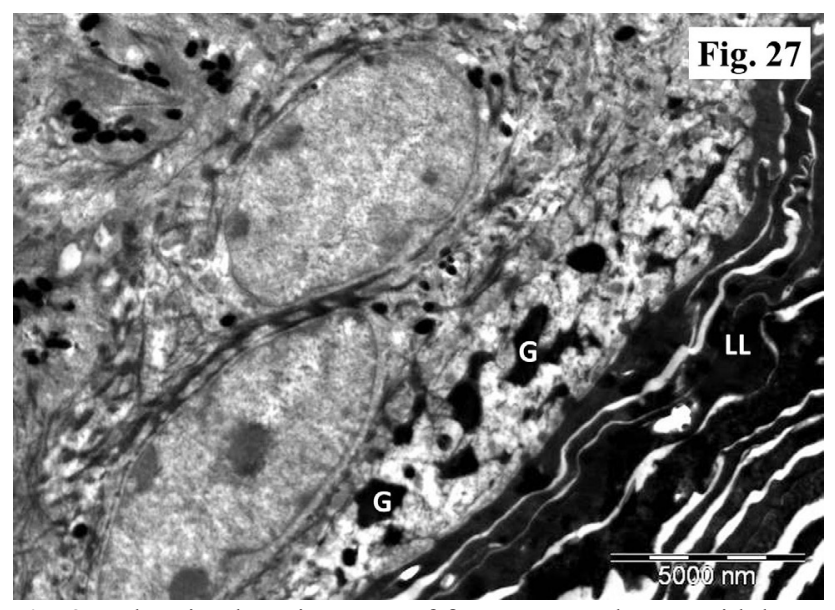

Fig. 27: Showing keratinocytes of stratum granulosum with large content of keratohyalin granules (G). The lipid lamellae (LL) at the stratum corneum-stratum granulosum interface are multiple and ample.

(Photoaged ASCs-treated subgroup, TEM x 4400)

\section{DISCUSSION}

Adipose derived stem cells in the present work were isolated from healthy human donors. Flow cytometry was used for their immunophenotypic identification. The isolated ASCs in the current work were found positive to CD34+, CD90+, CD105+ and negative for CD31 and CD45, which followed the International Federation for Adipose Therapeutics and Science and the International Society for Cellular Therapy criteria [28]. The absence of CD31 (endothelial marker) and CD45 (hematopoietic marker) in the ASCs isolate confirmed the lack of other unwanted cellular fractions prior to injection. The osteogenic differentiation potential of ASCs was also 
confirmed as Alizarin Red S stain was found bound to calcium indicating new bone matrix deposition. This was in accordance with other researchers who stated that culturing ASCs in osteogenic differentiation media for four weeks guided the cells to differentiate into osteoblast-like cells which then started to produce calcium phosphate within the extracellular matrix $(\mathrm{ECM})^{[30]}$.

In the current study, the presence and survival of injected human ASCs in the skin of guinea pigs was confirmed by labeling the cells with $\mathrm{PKH} 26$ prior to injection. A similar outcome was obtained in previous researches that used PKH26 cell-tracking dye to verify the persistence of human ASCs into the skin of hairless mice for two weeks ${ }^{[31]}$, and sheep for one month ${ }^{[32]}$.

The UV-induced photoaging in subgroup IIA, in the present study, significantly decreased the epidermal thickness. The restricted ability of epidermal cells to proliferate was previously demonstrated where Ali and his colleagues noticed the down-regulation of keratinocyte differentiation markers at early time after exposure to $\mathrm{UVB}^{[33]}$. Mitotic figures were hardly seen in epidermal keratinocytes which might add to the significant decrease in the thickness of epidermis.

Epidermal keratinocytes in the basal and prickle cell layers of the photoaged subgroup (IIA), in the present work, showed many degenerative features (cytoplasmic vacuolization, pyknotic nuclei, disrupted hemidesmosomes). This was in accordance with a recent study that considered UVB a powerful apoptotic trigger in vitro. The UVB detrimental effects were attributed to the upregulation of mitochondrial cytochrome $\mathrm{C}$ which was responsible for UVB-induced reactive oxygen species (ROS) formation and the activation of caspases that initiated a proteolytic cascade leading to UVB-induced cell death ${ }^{[34]}$. Elevated ROS levels were also claimed to be responsible for premature aging of the epidermal stem cells through damaging both nuclear and mitochondrial DNA with defective DNA repair mechanisms ${ }^{[35]}$. Disrupted hemidesmosomes detected in the present study was in accordance with previous investigators who explained this effect by secretion of large amounts of matrix metalloproteinase enzymes (MMPs) by dermal fibroblasts. These MMPs could degrade the components of epidermal basal lamina detaching it from basal keratinocytes ${ }^{[36]}$. Fragmented stratum corneum also seen after UV irradiation was consistent with the decrease in keratohyalin granules content in the stratum granulosum noticed in subgroup IIA TEM sections. Since keratohyalin granules contain filaggrin protein responsible for binding keratin filaments together ${ }^{[37]}$, the decrease in keratohyalin granules amount in the present study may explain the development of a defective physical skin barrier following UV exposure. In addition, the sparse lipid lamellae at the interface between keratinocytes of strata granulosum and corneum, most probably, adds to the impairment of epidermal skin barrier. This might be attributed to the decrease in the epidermal capacity to generate lamellar bodies that deliver lipid precursors and hydrolytic enzymes to gaps of stratum corneum lamellae to share in the barrier formation ${ }^{[38]}$. The therapeutic effects of the injected ASCs were detected in the current study. The apparent improvement of photoaged epidermis was most likely derived from ASCs paracrine antioxidant effects. Evidence from previous studies suggested that ASCs possessed potent antioxidant effects on the epithelial cells. They were found to secrete antioxidant enzymes as superoxide dismutase which scavenged excess ROS in the cells ${ }^{[39]}$.

The anti-melanosome HMB45 is a membranebound melanosomal protein that acts as a regulator of melanogenesis, involved in the transition from stage I to stage II melanosome maturation ${ }^{[40]}$. Hence, it has been considered a marker of melanocyte activation $^{[41]}$ and may be seen in a minority of normal adult melanocytes ${ }^{[42]}$. The results of immunostaining with anti-melanosome HMB45 in the present study indicated increased content of immature melanosomes after melanocytes' activation by UV irradiation. This might reflect loss of terminal differentiation and initiation of melanocyte proliferation ${ }^{[43]}$. The ASCs-treated subgroup IIB showed significant decrease in the melanin content when compared to the photoaged untreated subgroup IIA. The proposed mechanisms to the decreased melanin production and whitening effects of ASCs included their paracrine secretion of TGF- $\beta$, which down-regulate tyrosinase enzyme thus decreased melanin synthesis. Also, interleukin 6 secreted by ASCs was proved to inhibit melanocyte proliferation and melanin synthesis by down-regulating melanogenic enzymes ${ }^{[4]}$.

In the current study, dermal thickness was significantly decreased in the photoaged subgroup IIA with a significant decline in the collagen content as compared to the control group. Obvious decrease of collagen affects markedly the dermal thickness as it composes over $90 \%$ of the skin's total proteins ${ }^{[45]}$. In addition, UV-induced excess ROS production which overwhelms the skin anti-oxidative defense mechanisms resulting in premature dermal aging. These ROS could activate intracellular signaling pathway leading to increase in the expression of nuclear factor activator protein-1 (AP-1). This protein interferes with new procollagen synthesis by blocking the effect of transforming growth factor- $\beta$ (TGF- $\beta$ ), the most potent cytokine stimulating collagen production in vivo. Also, amplified AP-1 transcription induced collagen degradation by upregulating MMPs production in both fibroblasts and damaged keratinocytes $^{[9]}$. Moreover, although UVB had short wave lengths, about $5 \%$ of UVB rays could reach dermal papillae and affect dermal fibroblasts ${ }^{[46]}$. Coinciding, 
degenerated fibroblasts were detected in the photoaged subgroup of the present study. Previous reports stated that UVB irradiation decreased the proliferation of human dermal fibroblasts in culture with induction of apoptotic cell deaths ${ }^{[24]}$. This also goes well with the demonstrated decrease in collagen synthesis in the present work. In addition, treatment by ASCs in subgroup IIB showed an increase in total dermal thickness and in dermal collagen content as compared to the UV irradiated subgroup IIA. These regenerative effects might be attributed to the release of growth factors improving the dermal vasculature $^{[47]}$. Also, the ASCs paracrine factors were suggested to increase dermal collagen by activation of local fibroblasts to synthesize collagen and by reversal of UVB-induced apoptosis. It was also reported that ASCs decreased MMPs expression ${ }^{[48]}$, and had a major effect on human dermal fibroblast migration and expression of type I collagen in the culture ${ }^{[49]}$.

The focal depositions of elastotic material seen in dermis of the photoaged subgroup IIA explained the significant increase in elastic fibers content in comparison to both control group and ASCstreated subgroup IIB. The morphologic changes in sun-damaged skin associated with accumulation of elastin in the superficial dermis, was known as solar elastosis ${ }^{[50]}$, considered pathognomonic for photoaging and were contributed to the continuous upregulation of dermal elastases "elastin-degrading enzymes" in UVB irradiated $\operatorname{skin}^{[51]}$. Soluble cytokines secreted by UVB-exposed keratinocytes as interleukin- $1 \alpha$ (IL-1 $\alpha$ ) and granulocyte/macrophage colony-stimulating factor (GM-CSF) were hypothesized to pass through the basement membrane into the dermis. They might urge dermal fibroblasts to increase their expression of fibroblast elastase which degrade elastic fibers ${ }^{[52]}$. This could explain the fragmented elastic fibers noticed in the present study. Interestingly, treatment with intradermal injection of ASCs in the present study revealed significant decrease in the elastic content which might indicate the absence of elastosis as compared to the UV exposed subgroup IIA. Similarly, previous researchers detected a decrease in the solar elastosis upon ASCs injection into human skin, with the formation of new elastic fibers in the dermis. Therefore concluded that ASCs modified the pattern of dermal elastic fibers representing a skin rejuvenation effect ${ }^{[33]}$.

Distorted hair follicles with apparently fewer numbers and signs of cellular degeneration were detected in the photoaged untreated subgroup IIA in the present study might be attributed to degradation of the free fatty acids and the cholesterol of the integral hair lipid (IHL) of the hair follicles by both UVA and UVB ${ }^{[54]}$. The IHL was normally found on the inner root sheath and on the hair cuticle creating an environmentally resistant lipid envelope. It is usually regarded as a hair barrier similar to the epidermal skin barrier. The presence of many pyknotic nuclei in the hair follicles of the UV irradiated subgroup IIA in the current study could also be attributed to the direct damaging effects of ultraviolet rays. According to a very recent study, photoaging is characterized by epidermal atrophy that has been linked to UV damage on the stem cells of the basal layer and of the hair follicles ${ }^{[55]}$. Treatment by ASCs injection in the present study revealed apparent increase in the hair number. It was proposed that ASCs might promote hair regeneration by increasing proliferation of hair follicular cells through modulation of cell cycle. Besides, they could protect the dermal papilla cells from cytotoxic injury by $\operatorname{ROS}^{[56]}$.

\section{CONCLUSION}

ASCs could ameliorate photoaging effects on thin skin and partially restore its structural appearance. Further research is recommended to determine the optimal dose and frequency of ASCs administration for full reversal of the UV skin damaging effects.

\section{CONFLICT OF INTEREST}

There are no conflicts of interest

\section{REFERENCES}

1. Ganceviciene R, Liakou AI, Theodoridis A, Makrantonaki E, Zouboulis CC. Skin antiaging strategies. Dermato-Endocrinology 2012; 4(3): 308-319.

2. Lastowiecka-Moras E, Bugajska J, Mlynarczyk, B. Occupational Exposure to Natural UV Radiation and Premature Skin Ageing. International Journal of Occupational Safety and Ergonomics 2014; 20 (4): 639 -645.

3. Gilchrest BA. Photoaging. Journal of Investigative Dermatology 2013;133: E2-E6.

4. Grether-Beck S, Wlaschek M, Krutmann J, ScharVetter-Kochanek K. Photodamage and photoaging-prevention and treatment. Journal der Deutschen Dermatologischen Gesellschaft (Journal of the German Society of Dermatology): JDDG 2005; 3: S19-S25.

5. Imokawa G. Mechanism of UVB-induced wrinkling of the skin: paracrine cytokine linkage between keratinocytes and fibroblasts leading to the stimulation of elastase. J. Investig. Dermatol. Symp. Proc 2009; 14: 36- 43.

6. Yokose U, Hachiya A, Sriwiriyanont P, Fujimura 
T, Visscher MO, Kitzmiller WJ, Bello A, Tsuboi R, Kitahara T, Kobinger GP and Takema, Y. The endogenous protease inhibitor TIMP1 mediates protection and recovery from cutaneous photodamage. Journal of Investigative Dermatology 2012; 132(12), 2800- 2809.

7. Kim W, Park B, Sung J. Protective role of adipose-derived stem cells and their soluble factors in photoaging. Arch Dermatol Res 2009; 301: 329- 336 .

8. Reinau D, Achermann C, Arnet N, Meier CR, Hatz C, Surber C. Sun protective behaviour of vacationers spending holidays in the tropics and subtropics. British Journal of Dermatology 2014; 171(4): 868 -874.

9. Kohl E, Steinbauer J, Landthaler M, Szeimies RM. Skin ageing. Journal of the European Academy of Dermatology and Venereology 2011; 25(8): $873-884$.

10. Chien A, Cheng N, Shin J, Patel M, Hqinds G, Zang J, Suh H, Leung S, Summerer B, Daya N, Ghazarian S. Topical retinol, a precursor to tretinoin, can deliver comparable efficacy to tretinoin in treatment. $\mathrm{J}$ Invest Dermatol 2012; 132: S93-S93.

11. Ghersetich I, Tripo L, Garzitto A, Lotti TM. Chemical peelings. In: Katsambas, A., Lotti, T., Dessinioti, C. and D'Erme, A.M. eds. European Handbook of Dermatological Treatments. Springer 2015: 1115- 1127.

12. Davis EC, Callender VD. Aesthetic dermatology for aging ethnic skin. Dermatol Surg 2011; 37(7): 901-917.

13. Bradley EJ, Griffiths CE, Sherratt MJ, Bell M, Watson RE. Over-the-counter anti-ageing topical agents and their ability to protect and repair photoaged skin. Maturitas 2015; 80(3): 265 -272.

14. Hodges AL, Walker DK. Skin Care for Women. Nursing for Women's Health 2017; 20(6), 609- 613.

15. Harman RJ. Stem cell therapy in veterinary dermatology. Veterinary Dermatology 2013; 24(1): 90-e24.

16. Gimble JM, Katz AJ, Bunnel BA. Adiposederived stem cells for regenerative medicine. Circ Res 2007; 100: 1249- 1260.
Beuttler MM, Pandey AC, Gimble JM, Zhang S, Scruggs BA, Strong AM, Strong TA, Bunnell B. Comparison of human adult stem cells from adipose tissue and bone marrow in the treatment of experimental autoimmune encephalomyelitis. Stem cell research \& therapy 2014; 5(2): 1- 11.

18. Avci P, Sadasivam M, Gupta A, De Melo WC, Huang YY, Yin R, Chandran R, Kumar R, Otufowora A, Nyame T, Hamblin MR. Animal models of skin disease for drug discovery. Expert opinion on drug discovery 2013; 8(3): 331- 355.

19. Hanamura T, Uchida E, Aoki H. Skin-lightening effect of a polyphenol extract from Acerola (Malpighia emarginata DC) fruit on UV-induced pigmentation. Bioscience, Biotechnology, and Biochemistry 2008; 72(12): 3211 -3218.

20. Yao CL, Su GF. Research of bone marrow mesenchymal stem cells curing photoaging of guinea pig skin. Chinese Journal of Aesthetic Medicine 2008; 5: 030 .

21. Park HE, Lee J, Gonza'lez S, Middelkamp-Hup MA, Kapasi S, Peterson S, Gilchrest BA. Topical Application of a Protein Kinase C Inhibitor Reduces Skin and Hair Pigmentation. J Invest Dermatol 2004; 122: 159- 166.

22. Pallua N, Kim BS. The Role of Adipose TissueDerived Stem Cells and of Angiogenesis. Stem Cells in Aesthetic Procedures. Springer 2014: 327 -333.

23. Markarian CF, Frey GZ, Silveira MD, Milani AR, Ely PB, Horn AP, Nardi NB, Camassola M. Isolation of adipose-derived stem cells: a comparison among different methods. Biotechnology letters 2014; 36(4): 693 -702.

24. Kim WS, Park BS, Park SH, Kim HK, Sung JH. Antiwrinkle effect of adipose-derived stem cell: activation of dermal fibroblast by secretory factors. Journal of dermatological science 2009; 53(2): 96- 102.

25. Baer PC, Geiger H. Adipose-derived mesenchymal stromal/stem cells: tissue localization, characterization, and heterogeneity. Stem cells international 2012: 1 -11.

26. Suvarna SK, Layton C, Bancroft JD. Bancroft's theory and practice of histological techniques, 7th edition, Churchill Livingstone, El Sevier 2013: 203, 500 . 
Histological Techniques: An Introduction for Beginners in Toxicology. Royal Society of Chemistry 2014: 237 -238.

28. Kamyab-Hesari K, Mohtasham N, Aghazadeh N, Biglarian, M, Memar B, Kadeh H. The expression of MMP-2 and Ki-67 in head and neck melanoma, and their correlation with clinicpathologic indices. Journal of cancer research and therapeutics 2014; 10(3): 696.

29. Bourin, P, Bunnell BA, Casteilla L, Dominici M, Katz AJ, March KL, Redl H, Rubin JP, Yoshimura K, Gimble JM. Stromal cells from the adipose tissue-derived stromal vascular fraction and culture expanded adipose tissue-derived stromal/ stem cells: a joint statement of the International Federation for Adipose Therapeutics and Science (IFATS) and the International Society for Cellular Therapy (ISCT). Cytotherapy 2013; 15(6): 641- 648 .

30. Tsuji W, Rubin JP, Marra KG. Adipose-derived stem cells: Implications in tissue regeneration. World J Stem Cells 2014; 6(3): 312- 321.

31. Park BS, Kim WS. Adipose-derived stem cells and their secretory factors for skin aging. In Textbook of Aging Skin. Springer 2010: 201 -212.

32. Godoy-Zanicotti D, Coates DE, Duncan WJ. In vivo bone regeneration on titanium devices using serum-free grown adipose-derived stem cells, in a sheep femur model. Clinical oral implants research 2016; 28:64- 75 .

33. Ali N, Hosseini M, Vainio S, Taieb A, CarioAndré M, Rezvani HR. Skin equivalents: skin from reconstructions as models to study skin development and diseases. British Journal of Dermatology 2015; 173(2): 391- 403.

34. Salucci S, Burattini S, Curzi D, Buontempo F, Martelli AM, Zappia G, Falcieri E, Battistelli M. Antioxidants in the prevention of UVB-induced keratinocyte apoptosis. Journal of Photochemistry and Photobiology B: Biology 2014;141: 1 -9.

35. Panich U, Sittithumcharee G, Rathviboon N, Jirawatnotai S. Ultraviolet radiation-induced skin aging: the role of DNA damage and oxidative stress in epidermal stem cell damage mediated skin aging. Stem cells international 2016: 1- 37.

36. Amano S. Characterization and mechanisms of photoageing-related changes in skin. Damages of basement membrane and dermal structures. Experimental dermatology 2016; 25(S3): 14- 19.
37. Ross MH, Pawlina W. "Histology: A Text and Atlas: With Correlated Cell and Molecular Biology". $7^{\text {th }}$ ed. Lippincott Williams \& Wilkins Philadelphia, United States 2015: 493.

38. Bak H, Hong SP, Jeong SK, Choi EH, Lee SE, Lee SH, Ahn SK. Altered epidermal lipid layers induced by long term exposure to suberythemal dose ultraviolet. International journal of dermatology 2011; 50(7): 832- 837.

39. Zhang S, Dong Z, Peng Z, Lu F. Anti-aging effect of adipose-derived stem cells in a mouse model of skin aging induced by D-galactose. PloS one 2014; 9(5): e97573.

40. Slominski A. Coming of age of melanogenesisrelated proteins. Arch Pathol Lab Med. 2002; 126(7):775- 777.

41. Abdel-Naser MB, Krasagakis K, Garbe C, Eberle J. Photodermatol Photoimmunol Photomed. 2003; 19(3):122- 7.

42. Carlson JA, Ross JS, Slominski AJ. New techniques in dermatopathology that help to diagnose and prognosticate melanoma. Clin Dermatol. 2009; 27(1):75- 102

43. Lu S, Slominski A, Yang S, Sheehan C, Ross J, and Carlson JA. The correlation of TRPM1 (Melastatin) mRNA expression with microphthalmia-associated transcription factor (MITF) and other melanogenesis-related proteins in normal and pathological skin, hair follicles and melanocytic nevi. J Cutan Pathol. 2010; 37(Suppl 1): 26- 40.

44. Kruglikov IL, Scherer PE. Dermal Adipocytes: From Irrelevance to Metabolic Targets? Trends in Endocrinology \& Metabolism 2016;27(1): 1- 10.

45. Enggalhardjo M, Wahid S, Sajuthi D, Yusuf I. Effect of Adipose-derived Mesenchymal Stem Cells in Photoaging Balb/C Mouse Model. American Journal of Medical and Biological Research 2015;3(1): 48- 52.

46. Röck K, Grandoch M, Majora M, Krutmann J, FischerJW. Collagen Fragments InhibitHyaluronan Synthesis in Skin Fibroblasts in Response to UltravioletB(UVB). New InsightsintoMechanisms of Matrix Remodeling. Journal of Biological Chemistry 2011; 286(20): 18268- 18276.

47. Derby BM, Dai H, Reichensperger J, Cox L, Harrison C, Cosenza N, Yang M, Bueno RA, Neumeister MW. Adipose-Derived Stem Cell 
to Epithelial Stem Cell Transdifferentiation. Aesthetic Surgery Journal 2014; 34(1): 142 -153.

48. Son WC, Yun JW, Kim BH. Adipose-derived mesenchymal stem cells reduce MMP-1 expression in UV-irradiated human dermal fibroblasts: therapeutic potential in skin wrinkling. Bioscience, biotechnology, and biochemistry 2015; 79(6), 919- 925.

49. Lee DE, Ayoub N, Agrawal DK. Mesenchymal stem cells and cutaneous wound healing: novel methods to increase cell delivery and therapeutic efficacy. Stem cell research \& therapy $2016 ; 7(37), 1-8$.

50. Nikolakis G, Makrantonaki E, Zouboulis CC. Aging Skin as a Diagnostic Tool for Internal Diseases: A Chance for Dermatology. In pp. In: Farage, M.A., Miller, K.W. and Maibacheds, H.I. eds. Textbook of Aging Skin. Springer 2015;1 -17.

51. Nakajima H, Yoshioka R, Ezaki Y, Nagai $T$, Imokawa G. Paracrine cytokine interaction between UVB-exposed epidermal keratinocytes and dermal fibroblasts in stimulating expression of skin fibroblast-derived elastase. Cytokine 2012; 59(1): 166- 175.
52. Hiroaki N, Yoshiyuki E, Tomoyashu N, Ryosuke Y, Genji, I. Epithelial-mesenchymal interaction during UVB-induced up-regulation of neutral endopeptidase. Biochemical Journal 2012; 443(1): 297- 305 .

53. Charles-de-Sá L, Gontijo-de-Amorim NF, Takiya CM, Borojevic R, Benati D, Bernardi P, Sbarbati A, Rigotti G. Antiaging treatment of the facial skin by fat graft and adiposederived stem cells. Plastic and reconstructive surgery 2015; 135(4), $999-1009$.

54. Lee WS. Integral hair lipid in human hair follicle. Journal of dermatological science 2011; 64(3): 153- 158.

55. Truchuelo MT, Jiménez N, Miguel-Gomez L, Hermosa A, Sánchez-Neila, N, Cuevas J. Histological and Immunohistochemical Evaluation of the Efficacy of a New Cosmetic Formulation in the Treatment of Skin Photoaging. Dermatology Research and Practice 2017, 1- 10.

56. Park BS, Kim S. Adipose-Derived Stem Cells and Their Secretory Factors for Skin Aging and Hair Loss. Textbook of Aging Skin 2017; 205- 224. 
الملخص العربى

تأثير الخلايا الجذعية المستخلصة من النسيج الدهي على الثيخوخة المستحدثة في جلا الخنزير الغيني البالغ نتيجة التعرض للضوء: دراسة هستولوجية ولية و هيستوكيميائية مناعية

\section{سومية عبد العليم محمد، نفرث فريد عبد السلام، نجوى قسطندي قليني، نيفين بهاء الدين محمد

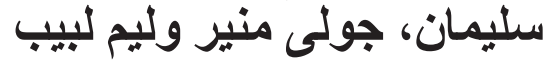

قسم علم الأنسجة و بيولوجيا الخليه ، كلية الطب- جامعة عين شمس، القاهرة، مصر

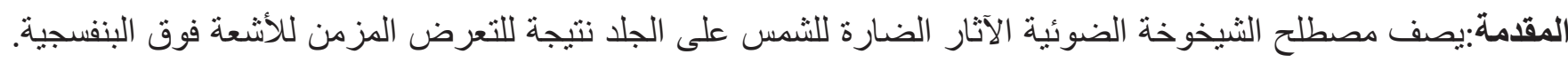

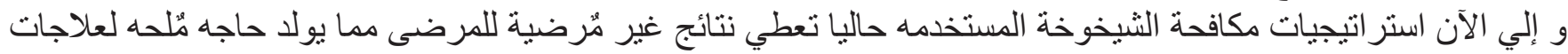

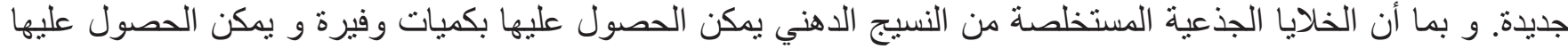

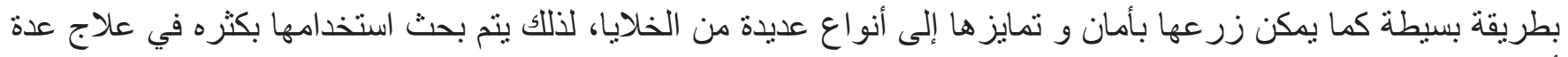

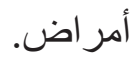

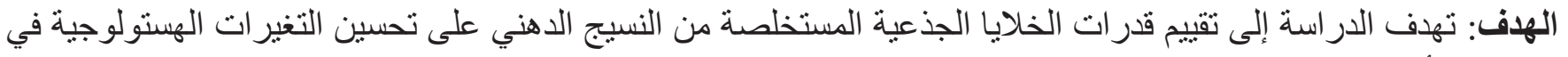

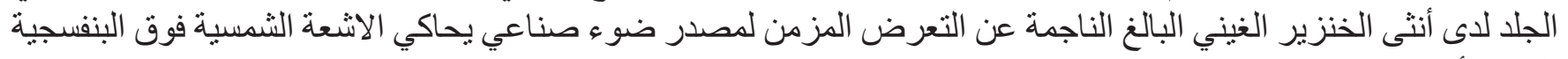

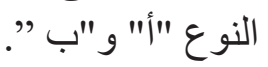
المواد والطرق: تم فصل الخلايا الجذعية من النسيج الدهني الأبيض الموجود تحت الجلد من خلال عملية شفط الدهون لخمسة

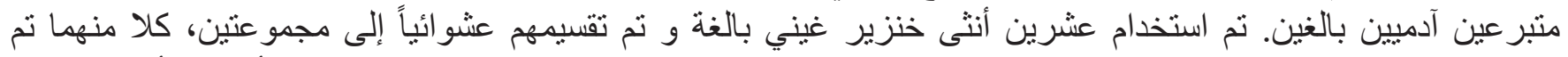

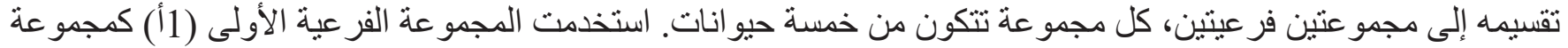

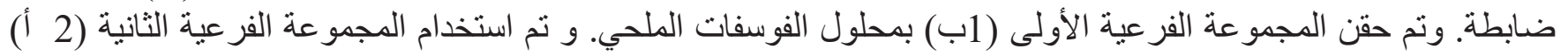

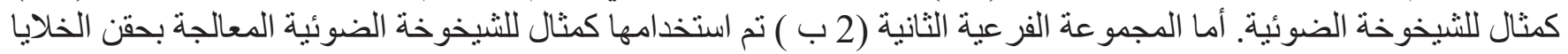

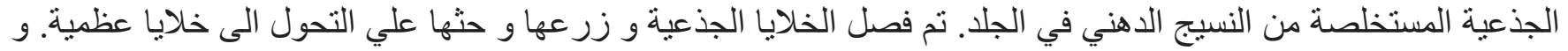
قد تم تحضير عينات الجلد و فحصها بإستخدام طرق هستولوجية و هستوكميائية مناعية. كما تم عمل دراسات قياسية النية وتحلياتيا إحصائياً.

النتائج: أظهرت المجموعة الفر عية الثانية (2 أ) عدة تأثير ات ضارة للأشعة فوق البنفسجية في طبقتي البشرهو و أدمة الجلد بينما أدى حقن الخلايا الجذعية المستخلصة من النسيج الدهني في المجموعة الفرعية الثانية (2 ب ) إلى إصلاحاً جزئيا في تركيبة الجلد.

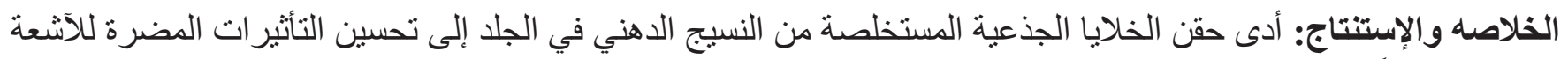

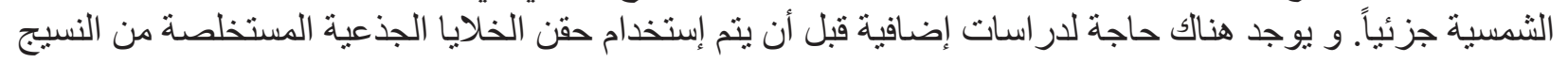

